\title{
Pharetra fidei contra iudaeos: Sus fuentes y una edición de trabajo*
}

\author{
Isaac Lampurlanés** \\ Università degli Studi di Padova \\ ORCID ID: https://orcid.org/0000-0002-7307-6167
}

El género literario del Adversus iudaeos fue muy extendido y cultivado durante toda la Edad Media, cuya estructura es la forma de diálogo/disputa entre la fe cristiana y la judía para concluir en la superioridad y/o veracidad de la primera ante la segunda. Aquí ofrecemos una edición de trabajo de la obra de polémica antijudía Pharetra fidei contra iudaeos, un texto muy popular y difundido a partir del siglo XIII por toda Europa, tal como demuestran los más de cien manuscritos que la conservan. Además, se presentará un estudio preliminar que relaciona esta obra con los Errores iudaeorum de Thibaud de Sézanne, el texto que acompaña a la Pharetra en numerosos códices. Localizamos, además, las fuentes principales de las que bebe la Pharetra.

Palabras clave: Pharetra fidei; polémica antijudía medieval; Thibaud de Sézanne; Errores iudaeorum; Isidoro de Sevilla; Flavio Josefo.

Pharetra fidei contra iudaeos: Its Sources And a Working Edition. - The literary genre of the Adversus iudaeos was wide-spread during the Middle Ages, offering a dialogue/disputation between the Christian faith and the Jewish one, leading to the conclusion that the former prevailed over the latter. In this paper we present a working edition of the anti-Jewish polemical work Pharetra fidei contra iudaeos, which was very popular and spread from the thirteenth century onwards across Europe, as is shown by the more than one hundred manuscripts that contain it. Additionally, we provide a preliminary study concerning the context of the work in comparison with another work which usually goes with it in the manuscripts, that is the Errores Iudaeorum by Thibaud de Sézanne, as well as considering the most important sources on which the Pharetra relies.

Keywords: Pharetra fidei; Medieval anti-Jewish Polemics; Thibaud de Sézanne; Errores iudaeorum; Isidore of Seville; Josephus.

* Este estudio ha sido elaborado en el marco del proyecto "El poder vivido en la baja edad media: percepción, representación y expresividad en la Gestión y recepción del poder (PV-PRE)" (PID2019-104085GB-100).

** isaac.lampurlanes@unipd.it

Copyright: (C) 2020 CSIC. Este es un artículo de acceso abierto distribuido bajo los términos de la licencia de uso y distribución Creative Commons Reconocimiento 4.0 Internacional (CC BY 4.0). 


\section{INTRODUCCIÓN}

La literatura cristiana, desde sus orígines, ha generado una textualidad que proyectaba una separación y distanciamiento de su origen judío, procurando así una justificación como religión independiente. Una vez asentada esta como ente individuado, siendo el cristianismo la religión del poder, sus intelectuales enfatizaron las diferencias - peyorativas en el caso de los judíos- que existían entre ambas confesiones, dando origen al género Adversus iudaeos ${ }^{1}$. Esta literatura se cultivó extensamente durante toda la Edad Media y evolucionó al mismo tiempo que los centros culturales e intelectuales cristianos ${ }^{2}$. En este contexto literario es donde debemos inscribir la obra Pharetra fidei contra iudaeos (a partir de ahora Pharetra fidei), la cual pretende ser un manual de polémica contra los judíos, a tenor de su prólogo ${ }^{3}$. Dicho tratado formaría parte de lo que Funkenstein ${ }^{4}$ señalaba como primer patrón de la controversia antijudía, que engloba un tipo de tratados Adversus iudaeos que argumenta sobre la mesianidad de Jesús a partir de diversos pasajes del Antiguo Testamento. Asimismo, una vez probada la verdad cristiana, este grupo critica y reprueba la obcecación del judaísmo, hasta el punto de justificar los males que el pueblo judío ha sufrido como consecuencia de su obstinación en negar a Jesucristo y haber cometido deicidio (sic).

La Pharetra fidei es una obra que merece gran atención dada la gran popularidad de la que gozó, puesto que la transmiten más de cien ma-

${ }^{1}$ Para estudios concretos de autores y sus obras de dicho género véase, entre otros: Heinz Schreckenberg, Die christlichen Adversus-Judaeos-Texte und ihr literarisches und historisches Umfeld (1.-11-Jh.) (Frankfurt: Peter Lang, 1999); Carmen CARDELLE De Hartmann, Lateinische Dialoge 1200-1400. Literaturhistorische Studie und Repertorium (Leiden-Boston: Brill, 2007), y A. Lukyn Williams, Adversus Judaeos. A Bird'sEye View of Christian Apologiae Until the Renaissance (Nueva York: Cambridge University Press, 2012).

2 Jeremy CoHEN, «Scholarship and Intolerance in the Medieval Academy: The Study and Evaluation of Judaism in European Christendom», The American Historical Review 91:3 (1986) págs. 592-613: 593.

3 Véase en el apéndice de este artículo, líneas 2-11.

4 Amos Funkenstein, «Basic Types of Christian Anti-Jewish Polemics in the Later Middle Ages», Viator 2 (1971) págs. 373-382. 
nuscritos ${ }^{5}$. También es de interés la relación que guarda con los Errores iudaeorum de Thibaud de Sézanne, una obra también de polémica antijudía que la acompaña (antecediéndola o siguiéndola) en muchos códices. Dicha relación, a veces casi inseparable, ha provocado que tengamos versiones de la Pharetra fidei que se apartarían de su forma primaria, de manera que los estudiosos incurrieran en equívocos al nombrarla. Como apunta Carmen Cardelle ${ }^{6}$ comúnmente se le ha llamado Pharetra al conjunto de Pharetra fidei y Errores iudaeorum al ser la Pharetra fidei la primera en sucesión en la mayoría de los casos, mientras que, en origen, por su forma y contenido, debían ser dos obras independientes que un compilador reunió. Esta asociación, a su vez, ha ocasionado que se pensara que el autor de los Errores, Thibaud de Sézanne, era también el autor de la Pharetra fidei $i^{7}$ (o del compendio que denominan Pharetra). Asimismo, su interrelación no solo ha inducido errores a sus lectores modernos, sino que en la misma Edad Media podemos encontrar reelaboraciones del compendio Pharetra fidei-Errores como una obra nueva y única, tal como presentó Moisés Orfali en su edición del Dialogus pro ecclesia contra synagogam ${ }^{8}$.

Con todo lo antedicho, en el presente trabajo presentaremos una primera edición de trabajo de la Pharetra fidei con la colación de 3 manuscritos. Estos se encuentran entre los códices más antiguos que contienen la obra y han sido elegidos para la edición por transmitir un

${ }^{5}$ Se pueden encontrar registros de los manuscritos que contienen la Pharetra fidei en los siguientes trabajos: Thomas Kaeppeli y Emilio Panella, Scriptores Ordinis Praedicatorum Medii Aevi. Volumen IV T-Z (Roma: Istituto Storico Domenicano, 1993) págs. 292-295; Heinz Pflaum, Die religiöse disputation (Ginebra: Olschki, 1935) pág. 79, nota 2, y Carmen Cardelle de Hartmann, «Drei Schriften mit dem Titel Pharetra fidei», Aschkenas - Zeitschrift für Geschichte und Kultur der Juden 11 (2001) págs. 327-349 y «El Dialogus pro ecclesia contra synagogam impreso por Pablo Hurus: autoría, fecha y transmisión manuscrita», Sefarad 62:1 (2002) págs. 3-19.

${ }^{6}$ Cardelle de Hartmann, «Drei Schriften», pág. 330.

7 Así lo recogen Kaeppeli y Panella (Scriptores Ordinis Praedicatorum, pág. 292) cuando dicen «Theobaldo OP suppriori Parisiensi perplures libri mss "Pharetram fidei contra Iudaeos" necnon accedentes "Errores Iudaeorum in Talmut" (1244-50 c.) ascribunt».

8 Moisés ORFALI, «El "Dialogus pro ecclesia contra synagogam" un tratado anónimo de polèmica antijudía», Hispania LIV:2 núm. 187 (1994) págs. 679-732. 
texto de la Pharetra representativo de los siglos XIII y XIV. Los manuscritos utilizados son los siguientes:

A Múnich, Bayerische Staatsbibliothek. clm. 16061, ff. 124v-130rb (s. XIV).

$B$ Múnich, Bayerische Staatsbibliothek. clm. 21573, ff. 1r-10v (s. XIII-XIV).

C Múnich, Bayerische Staatsbibliothek. clm. 14722, ff. 36r-43r (s. XIV).

A continuación, describimos la estructura de la Pharetra fidei y, sobre todo, las fuentes principales que usa. Consecuentemente, en comparación con el contexto y el contenido de la obra de los Errores iudaeorum de Thibaud de Sézanne, podremos aportar nuevos apuntes históricos y de composición de la hasta la fecha tan desconocida Pharetra fidei.

\section{Pharetra FideI: Estructura y COntenido}

Como hemos anticipado, la Pharetra fidei se enmarca en el vasto campo de las obras de controversia antijudía medievales que persiguen la refutación del judaísmo mediante la exposición de argumentos teológicos autorizados con citas de la Biblia. Se encuentra estructurada en 28 capítulos, cada uno de los cuales lleva por título lo que sería un argumento cristológico lato sensu ${ }^{9}$.

Sin embargo, la obra abre con dos prólogos: el primero da instrucciones al lector cristiano de cómo llevar una disputa contra un judío, y el segundo, que sigue al Incipit de la Pharetra fidei, nos presenta la obra (o mejor dicho el conjunto de Pharetra y Errores) como un arma para abatir al judío (caracterizado como Goliat).

9 Por ejemplo capítulos que dan pruebas, a partir de pasajes del Antiguo Testamento, de que el Mesías ya ha llegado (Quod Christus iam dudum venerit), que nació de una virgen (Quod de virgine natus est Christus), que este es Dios y hombre (Quod sit Deus et homo) y que nació en Belén (Quod in Bethlehem natus sit Christus Deus et homo); o incluso hay pasajes que justifican los infortunios de los judíos por no creer en Jesús como Mesías y por matarlo (De planctu iudaeorum qui Christum crucifixerunt; Quod pro nece Christi iudaei desolati et dispersi sunt), entre otros. 
El primer prólogo reproduce el tópico de la disputa real entre cristianos y judíos ${ }^{10} \mathrm{y}$ que el presente volumen quiere ser un manual para que el cristiano la conduzca exitosamente. Asimismo, en algunos lugares, el texto también nos da muestras de que el autor está "conversando" con el lector, dando "objeciones, réplicas" a las posibles contestaciones que el judío pueda dar, como Obiectio iudaei, Sed obiecit iudaeus (línea 52), Obiectio iudaeorum contra adventum Christi (línea 64), Ad hoc respondet iudaeus (línea 82), entre otras.

En cuanto al segundo prólogo, más breve y retórico, con un encabezamiento que lleva el título de la obra ${ }^{11}$, nos revela que esta obra tiene un origen múltiple (como ya apuntaba Cardelle). El discurso de este prólogo, sobre que una primera parte prueba la fe cristiana (es decir la Pharetra fidei) y una segunda donde revela los errores de los judíos (clara alusión a los Errores iudaeorum de Thibaud de Sézanne), también da indicio de este doble origen: el doble contenido al que alude y la mención que hace de los Errores permiten distinguirlo como el prólogo resultante de la suma de las dos obras (Pharetra fidei y Errores) y, por lo tanto, es un añadido del compilador de ambas obras.

\section{Fuentes de la Pharetra FideI}

La Pharetra fidei contra iudaeos se compone de diferentes fuentes latinas. En su mayoría, y en orden de importancia hemos podido identificar las siguientes:

${ }^{10}$ Se ha discutido, y continúa discutiéndose, el hecho de que estas disputas fueran reales o más bien ficticias, escenarios apropiados que los escritores representarían para exponer un diálogo entre las diferentes confesiones. En este sentido, Gilberto Crispín, en el prefacio de su Disputatio iudaei et christiani nos dice que el judío con el que hablaba estaba muy experimentado en discutir y disputar contra los cristianos; $c f$. Anna Sapir Abulafia y Gillian R. Evans, The Works of Gilbert Crispin Abbot of Westminster (Oxford: Oxford University Press, 1986) pág. 9: «Paternitati et prudentie tue discutiendum mitto libellum, quem nuper scripsi, pagine commendans que Iudeus quidam olim mecum disputans contra fidem nostram de lege sua proferebat et que ego ad obiecta illius pro fide nostra respondebam. Nescio unde ortus, sed apud Maguntiam litteris educatus, legis et litterarum etiam nostrarum bene sciens erat, et exercitatum in scripturis atque disputationibus contra nos ingenium habebat».

11 «Tolle arma tua pharetram et arcum», clara referencia a Génesis 27:3, aunque en la Vulgata aparece: «Sume arma tua faretram et arcum». 
2.1. De fide catholica contra iudaeos de Isidoro de Sevilla (556-636)

La obra apologética del obispo de Sevilla De fide catholica contra iudaeos es sin duda la fuente más determinante en la composición de la Pharetra fidei. Ello se puede notar ya en el prólogo cuando divide el opúsculo en dos partes y que la primera está dedicada a la probationem de fide catholica. Asimismo, encontramos en el texto referencias atribuídas a san Isidoro, como cuando dice Isidorus (línea 80), o sic expone secundum Isidorum (líneas 105-106), entre otros.

La fundamentación en el De fide catholica es evidente según la estructura de la Pharetra fidei y sus capítulos, cuyos títulos tienen un claro reflejo de los que encontramos en la obra de san Isidoro. Véase la correspondencia, si bien no exacta, de los títulos de ambas obras en la tabla siguiente:

\begin{tabular}{|l|l|}
\hline \multicolumn{1}{|c|}{ De fide catholica contra iudaeos ${ }^{12}$} & \multicolumn{1}{|c|}{ Pharetra fidei contra iudaeos } \\
\hline $\begin{array}{l}\text { Quia Christus de virgine sine virili } \\
\text { coitu genitus est (I, 10) }\end{array}$ & $\begin{array}{l}\text { III. Quod de virgine natus est Chris- } \\
\text { tus }\end{array}$ \\
\hline $\begin{array}{l}\text { Quia Filius Dei, Deus, homo factus } \\
\text { est (I, 5) }\end{array}$ & IV. Quod sit Deus et homo \\
\hline $\begin{array}{l}\text { In Bethlehem natus est Christus } \\
\text { (I, 11) }\end{array}$ & $\begin{array}{l}\text { V. Quod in Bethlehem natus sit } \\
\text { Christus Deus et homo }\end{array}$ \\
\hline A Deo Patre unctus est (I, 14) & $\begin{array}{l}\text { VI. Quod non oleo corporali, sed } \\
\text { paterno spiritu unctus est in regem et } \\
\text { sacerdotem }\end{array}$ \\
\hline $\begin{array}{l}\text { Quia pauper et abiectus primo ad- } \\
\text { ventu venit (I, 15) }\end{array}$ & $\begin{array}{l}\text { VII. Quod Christus pauper et abiec- } \\
\text { tus venit in mundum }\end{array}$ \\
\hline Iudaei non erant eum agnituri (I, 18) & $\begin{array}{l}\text { VIII. Quod eum non cognoverunt } \\
\text { iudaei }\end{array}$ \\
\hline Venundatus est (I, 20) & $\begin{array}{l}\text { IX. Quod Christus venditus est tri- } \\
\text { ginta argenteis }\end{array}$ \\
\hline
\end{tabular}

12 Entre paréntesis, colocamos el libro en número romano y el capítulo en número arábigo de la obra. 


\begin{tabular}{|l|l|}
\hline Comprehensus est (I, 23) & $\begin{array}{l}\text { X. Quod iudaei Christum propter in- } \\
\text { vidiam occiderunt }\end{array}$ \\
\hline $\begin{array}{l}\text { Pro nostris peccatis crucifixus est } \\
\text { (I, 43) }\end{array}$ & $\begin{array}{l}\text { XII. Quod Christus propter peccata } \\
\text { nostra passus est, non sua }\end{array}$ \\
\hline Descendit ad inferos (I, 51) & $\begin{array}{l}\text { XVIII. Quod sepultus fuit et descen- } \\
\text { dit ad inferna }\end{array}$ \\
\hline Resurrexit ab inferis (I, 54) & XIX. De resurrectione Christi \\
\hline In caelum ascendit (I, 56) & XX. De ascensione Christi \\
\hline $\begin{array}{l}\text { Christus post ascensionem suam Spi- } \\
\text { ritum sanctum super apostolos misit } \\
\text { (I, 59) }\end{array}$ & $\begin{array}{l}\text { XXI. De missione spiritus sancti in } \\
\text { discipulos }\end{array}$ \\
\hline $\begin{array}{l}\text { Apostoli variis linguis locuti sunt } \\
\text { (I, 60) }\end{array}$ & $\begin{array}{l}\text { XXII. Quod variis linguis apostoli } \\
\text { loquebantur }\end{array}$ \\
\hline $\begin{array}{l}\text { Iudaei propter peccatum in Christum } \\
\text { debellati atque dispersi sunt (II, 9) }\end{array}$ & $\begin{array}{l}\text { XXIV. Quod pro nece Christi iudaei } \\
\text { desolati et dispersi sunt }\end{array}$ \\
\hline $\begin{array}{l}\text { Quod peccatorum remissio futura } \\
\text { erat per baptismum (II, 24) }\end{array}$ & $\begin{array}{l}\text { XXV. De efficatia baptismi Christia- } \\
\text { norum }\end{array}$ \\
\hline $\begin{array}{l}\text { Quod, Veteri Testamento evacuato, } \\
\text { Novum futurum erat (II, 14) }\end{array}$ & $\begin{array}{l}\text { XXVIII. De mutatione legis veteris } \\
\text { in novam }\end{array}$ \\
\hline
\end{tabular}

La conexión entre la Pharetra fidei y el De fide catholica va más allá de seguir los capítulos empleados por el obispo de Sevilla, y encontramos una textualidad casi idéntica, con algunos cambios estilísticos, con dicha obra en numerosos pasajes como el que mostramos a continuación: 


\begin{tabular}{|c|c|}
\hline De & Pha \\
\hline $\begin{array}{l}\text { Haec enim nota omnibus causa est. } \\
\text { Judas enim, poenitentia motus, pecu- } \\
\text { niam reportavit, et projecit in tem- } \\
\text { plum, et abiit, et laqueo se suspendit. } \\
\text { Ut impleretur, quod dixerat Isaias: } \\
\text { Testis falsus non erit impunitus, pro } \\
\text { eo quod vendidit argento Justum } \\
\text { [Prv 19:5; Am } 2: 6] \text {. }\end{array}$ & $\begin{array}{l}\text { enim paenitenti } \\
\text { reportavit et pro } \\
\text { abiit et laqueo se } \\
\text { retur quod dixer } \\
\text { sus non erit in] } \\
\text { «pro eo quod } v \\
\text { tum» [Am 2:6]. }\end{array}$ \\
\hline $\begin{array}{l}\text { Quam pecuniam bene Dominus } \mathrm{m} \\
\text { cedem suam dixit; multa enim op } \\
\text { apud eos fecerat, reddens vitam m } \\
\text { tuis, lucem caecis, surdis auditu }\end{array}$ & $\begin{array}{l}\text { Quam pe } \\
\text { cedem su } \\
\text { eos opera } \\
\text { tuis, lum } \\
\text { gressum } \\
\text { nefandi } \\
\text { mortem t }\end{array}$ \\
\hline
\end{tabular}

Sin embargo, la labor del autor de la Pharetra no consistió meramente en copiar los pasajes del De fide catholica, con ciertos retoques de vocabulario y del orden de palabras, sino que reelabora la obra del obispo de Sevilla creando capítulos nuevos a partir del material que encuentra en un capítulo o en varios, o incluso incorpora nuevas citas bíblicas que van acorde con el argumento del capítulo en cuestión.

13 Isidorus Hispalensis, «De fide catholica contra iudaeos», en Patrologia latina cursus completus, ed. Jacques Paul Migne (Paris: J.P. Migne, 1850) vol. 83, cols. 449538: 478. Traducción al castellano en: Isidoro de Sevilla, Sobre la fe católica contra los judios, eds. Eva Castro Caridad y Francisco Peña Fernández (Sevilla: Secretariado de publicaciones de la Universidad de Sevilla, 2012) págs. 83-84. 


\begin{tabular}{|c|l|}
\hline De fide catholica contra iudaeos & \multicolumn{1}{|c|}{ Pharetra fidei contra iudaeos } \\
\hline $\begin{array}{l}\text { Cujus baptismi purificationem sic } \\
\text { Spiritus sanctus per eumdem prophe- }\end{array}$ & $\begin{array}{l}\text { Gratiam baptismi Dominus per Eze- } \\
\text { chielem praedixit trigesimo sexto }\end{array}$ \\
«Tollam quippe vos de gentibus, et & capitulo: «cum sanctificatus fuero in \\
congregabo vos de universis terris, et & de universis terris» [Ez 36:24] «et \\
adducam vos in terram vestram, et & effundam super vos aquam mundam \\
effundam super vos aquam mundam, & et mundabimini ab omnibus inquina- \\
et mundabimini ab omnibus inquina- & mentis vestris et ab universis idolis \\
mentis vestris.» Et, ut Novum Testa- & vestris mundabo vos et dabo vobis \\
mentum suscipiant, sic sequitur: «Et & cor novum et spiritum novum ponam \\
dabo vobis cor novum, et spiritum & in medio vestri» [Ez 36:25-26]. Fi- \\
novum ponam in medio vestri, et & gura baptismi praecessit in veteri \\
auferam cor lapideum de carne ves- & testamento, quia legitur quarto Re- \\
tra, et dabo vobis cor carneum, et & gum quinto quod cum Naaman Syrus \\
spiritum meum ponam in medio ves- & vir leprosus ex iussu Helysei septies \\
tri et faciam ut in praeceptis meis & in Iordane baptizatus est [cf. IV Rg \\
ambuletis, et judicia mea custodiatis, & $\underline{5,10], \text { ubi figuratur efficatia baptis- }}$ \\
et operemini [Ex 36:26-27].» ${ }^{14}$ & $\underline{\text { mi nostri qui primo in Iordane ince- }}$ \\
& pit. \\
\hline
\end{tabular}

Siendo evidente que este pasaje del capítulo De efficatia baptismi christianorum de la Pharetra se basa en el último párrafo del Quod peccatorum remissio futura erat per baptismum de San Isidoro, podemos ver que el autor de la Pharetra reformula la parte introductoria del pasaje bíblico de Ezequiel 36. Esta diferencia que podría pasar por meramente estilística se muestra relevante al final de la sección, donde observamos que la Pharetra aporta un añadido que no encontramos en su fuente, un ejemplo más de los beneficios del bautismo con la paráfrasis (ya que no es una cita literal) del pasaje del segundo de los Reyes 5 donde Heliseo cura la lepra a Naamán submergiéndolo en el Jordán. Así pues, vemos que nuestro autor, si bien en la mayoría de casos sigue la estructura argumentativa de probación del cristianismo de san Isidoro, la amplía y complementa.

${ }^{14}$ IsIDORus Hispalensis, «De fide catholica contra iudaeos», col. 533. 
Estas amplificaciones sobre el texto de san Isidoro dan lugar a localizar la segunda fuente principal con la que trabaja el autor de la Pharetra fidei: pasajes del De bello iudaico y de las Antiquitates iudaicae de Flavio Josefo.

\subsection{Flavio Josefo}

En el capítulo 24 sobre la desolación y diáspora de los judíos, el autor de la Pharetra se aparta, en cuanto a las referencias bíblicas que utilizan, a lo que se expone en el capítulo homólogo (Judaei propter peccatum in Christum debellati atque dispersi sunt) que encontramos en el De fide catholica ${ }^{15}$. Además, el capítulo de la Pharetra termina con la añadidura de una nueva fuente que, como en el pasaje que hemos presentado anteriormente, ofrece más ejemplos de las calamidades que han sufrido los judíos por la muerte de Jesús:

Quod pro Christi morte iudaei desolati et dispersi sunt dicit David in psalmo septuagesimo secundo: «quomodo facti sunt in desolationem subito defecerunt perierunt propter iniquitatem suam» [Ps 72:19 -LXX-]. Item psalmo nonagesimo tertio «Deus ultionum» [Ps 93:1 -LXX-]; «captabant in animam iusti et sanguinem innocentem condemnabunt» [Ps 93:21 -LXX-] «et reddet illis iniquitatem ipsorum et in malitia eorum disperdet eos disperdet illos Dominus Deus noster» [Ps 93:23 -LXX-]. Bis dicit disperdet, quia dispersit in mundum et disperdet in infernum. Item Danihel nono capitulo: «occidetur christus et non erit eius -populus qui eum negaturus est- et civitatem et sanctuarium dissipabit populus cum duce venturo -id est cum Tito-» [Dn 9:26]. Qualiter autem civitas Hierusalem propter necem Domini vastata sit per Titum et Vespasianum scribit Iosephus libro decimo quarto: sub Tito captivata sunt circa quindecim milia. Item quinquaginta et triginta quinque milia vendita. Item Hierusalem ascendi poterat congestione cadaverum et civitas plena cadaveribus ita quod etiam viae cadaveribus clauderentur et super cadavera iretur. Item in Iordane infiniti submersi sunt. Item plurium milium ventres exenterati sunt propter aurum quod glutiverant. Item sanguis largior fuit ut ignem extingueret. Item plura milia se ipsos occiderunt. Item triginta quinque milia se mutuo occiderunt. Item matres pueros comedebant. Haec Iosephus. Cum igitur iudaei saepe grandia peccata conmiserint, idolatriam et alia multa et numquam tam acriter puniti fuerint. Patet quod grande sit peccatum quod Christum crucifixerunt. Item

15 Isidorus HisPalENSIS, «De fide catholica contra iudaeos», cols. 514-515. 
Iosephus libro decimo octavo: Iacobus frater Iesu tantae fuit sanctitatis ut destructio Hierusalem et calamitas quam passi sunt iudaei per Titum eis acciderit propter necem Iacobi. Haec Iosephus. Cum autem idem Iacobus de pinnaculo templi praecipitatus fuerit pro eo quod Christi gloriam praedicavit et pro peccato mortis eius Hierusalem sit destructa, ut dicit Iosephus: Patet quod veritatem praedicaverat.

La parte subrayada del texto explica que la destrucción de Jerusalén por los emperadores Tito y Vespasiano, así como diferentes episodios sangrientos de la guerra, son también consecuencia divina del deicidio, $y$, como referencia, el autor nos indica que los ejemplos que él presenta se encuentran en la obra de Iosephus, es decir Flavio Josefo (37-100 d. C. ${ }^{16}$. Efectivamente, la Pharetra lo identifica adecuadamente cuando alude en varias secciones que cierto contenido proviene de dicho autor judío: scribit Iosephus (línea 409), Haec Iosephus (línea 417; 422), ut dicit Iosephus (línea 424), entre otros.

Hemos podido constatar, a través de la comparación textual, que podría derivar de la traducción latina de Rufino de Aquilea (345-411):

\begin{tabular}{|c|c|}
\hline Bellum iudaicum & Pharetra fidei \\
\hline $\begin{array}{l}\text { (III, V, 7) }{ }^{17} \text { jamque ascendi poterat } \\
\text { congestione cadaverum. }{ }^{18}\end{array}$ & $\begin{array}{l}\text { Item Hierusalem ascendi poterat } \\
\text { congestione cadaverum. }\end{array}$ \\
\hline $\begin{array}{l}\text { (VI, V, 1) videbatur autem sanguis } \\
\text { igne largior esse }^{19}\end{array}$ & $\begin{array}{l}\text { Item sanguis largior fuit ut ignem } \\
\text { extingueret }\end{array}$ \\
\hline
\end{tabular}

${ }^{16}$ La recepción latina de la obra de Flavio Josefo en la Edad Media llega a través de la traducción de Hegésipo (posible mala transliteración del nombre de Josefo) de finales del cuatro y principios del cinco, así como también otra traducción atribuída a Rufino de Aquilea por Casiodoro en sus Institutiones divinarum lectionum; cf. Claudio MoresChini y Enrico NoRelli, Manuale di letteratura cristiana antica greca e latina (Brescia: Editrice Morcelliana, 1999) págs. 366 y 467. Sobre el uso de la obra histórica de Flavio Josefo en tratados de carácter teológico en la Edad Media, véase Jussi HansKA, «Preachers as Historians. The Case of the Destruction of Jerusalem in 70 AD», Anuario de Estudios Medievales 42:1 (2012) págs. 29-52.

17 Los números corresponden, al libro, capítulo, sección, tal como está dividida la edición de la versión griega.

18 Flavius Iosephus, De bello judaico libri septem, trad. Rufinus Aquileiensis, ed. Edward CARDwell (Oxford: E. typographeo academico, 1837) pág. 192.

19 Flavius Iosephus, De bello judaico libri septem, pág. 342. 
Sin embargo, el resto de menciones a la obra de Flavio Josefo parecen ser paráfrasis de algunos de los pasajes del De bello iudaico como sucede con la mención que las madres se comían a sus hijos (Item matres pueros comedebant), que resume todo el pasaje de Josefo donde se nos explica, con mucho más detalle, el extremo de hambruna de una madre de nombre María, hija de Eleazar, en ese contexto de guerra ${ }^{20}$.

En esta misma línea, la Pharetra también nos ofrece otros extractos de la obra de Flavio Josefo que le servirá para conformar el vigésimo sexto capítulo titulado Testimonium Iosephi de Iohanne, donde se nos muestra que los judíos en el pasado ya han sufrido el castigo divino por haber dado muerte a dos hombres buenos, en dicho caso, a Juan Bautista y Jesús. A su vez, a través de la reproducción del controvertido Testimonium flavianum en la Pharetra, el autor da una nueva muestra de la mesianidad de Jesús (objetivo principal de la obra) apoyado, esta vez, por un historiógrafo de origen judío. En este pasaje, sin embargo, la fuente ya no es el Bellum iudaicum, sino más bien las Antiquitates iudaicae (especialmente el libro XVIII):

Hoc testimonium perhibet Iosephus Iohanni Baptistae dicens libro decimo octavo: Herodis exercitus ideo periit, quia in eum indignatio divina permota est pro vindicta Iohannis qui vocabatur Baptista. Hunc enim Herodes occidit virum valde bonum qui praecipiebat iudaeis virtuti operam dare, iustitiam colere in Deum pietatem servare. Tunc eum demum baptismum acceptabilem fore non solum si ad absolvenda peccata sumatur. Verum etiam ad sanctimoniam corporis et animae iustitiam purificationemque servetur omniumque pariter virtutum velut signaculum et custodia fidelis habeatur. Herodes veritus, ne doctrinae eius persuasione populi a regno eius discederent, occidit Iohannem. [Ant. XVIII, 5, 2]. Haec Iosephus. Idem Iosephus dicit: Fuit hisdem temporibus Iesus, vir sapiens, si eum tamen virum nominare fas est. Erat enim mirabilium operum effector et doctor eorum qui libenter quae vera sunt audiunt et multos iudaeorum et multos ex gentibus sibi adiunxit. Christus hic erat. Hunc accusatione primorum nostrae gentis cum Pilatus in cruce agendum decrevisset, non deserverunt qui ab initio eum dilexerunt. Apparuit eis iterum vivus, secundum quod prophetae vel haec vel alia de eo futura praedixerant, sed et in hodiernum diem Christianorum, qui ab ipso dicti sunt, et nomen perseverat et genus [Ant. XVIII, 3, 3]. Haec Iosephus.

${ }^{20}$ Flavius Iosephus, De bello judaico libri septem, págs. 336-337. 
Iosephus autenticus est apud iudaeos, sed testimonium de Christo dicunt ibi non esse. Sed tunc quaere si habeant ibi de rege Herode, et de Tito et Vespasiano quod si easdem habent historias, habent etiam de Christo nisi tunc eas sponte deleverint.

Los dos ejemplos de "hombres buenos y sabios" (virum balde bonum/ vir sapiens), con la inclusión del Testimonium flavianum, vienen correctamente referenciados como provenientes de la obra de Josefo (Haec Iosephus/Idem Iosephus dicit), e incluso nos ofrece la cita exacta del libro del que proceden (libro decimo octavo), si bien no nos dice que se trate de las Antiquitates iudaicae. Cabe decir que la narración de los ejemplos de Juan Bautista y Jesús en un mismo pasaje no es una novedad del autor de la Pharetra, pues ya se encuentra en el primer libro, capítulo 11, de la obra griega de Eusebio de Cesarea, Historia eclesiástica $^{21}$.

En esta ocasión, como en el caso de las referencias al Bellum iudaicum, nos inclinamos a pensar que la fuente latina que utilizó el autor anónimo de la Pharetra es la traducción de Rufino de Aquilea, tal como se observa en el siguiente pasaje de dicha obra y las claras correspondencias textuales que comparten:

...haec in octavo decimo antiquitatum libro his ipsis, quibus infra adnotatum est, syllabis scribit.

Quibus autem. inquit. Iudaeorum videbatur ideo perisse Herodis exercitum, quod in eum satis iuste ultio divina commota sit pro vindicta Iohannis qui vocabatur Baptista, quem punivit Herodes virum valde bonum, qui praecipiebat Iudaeis virtuti operam dare, iustitiam inter se invicem custodire et in deum servare pietatem, per baptismum in unum coire. hoc enim pacto baptismum acceptabile fore, si non solum ad abluenda peccata sumatur, verum et ad castimoniam corporis atque ad animae iustitiam purificationemque servetur omniumque pariter virtutum velut signaculum et custodia quaedam fidelis habeatur. quae cum ab eo per praecepta huiuscemodi docerentur atque ad audiendum eum perplurima multitudo concurreret, veritus Herodes, ne forte doctrinae eius persuasione populi a suo rege desciscerent. videbat enim, quod praeceptis eius ac monitis oboedire in omnibus plebs esset parata. melius credi-

21 Eusebir PamphiliI, «Historia ecclesiastica», en Patrologia graeca cursus completus, ed. Jacques Paul Migne (Paris: J.P. Migne, 1857) vol. 20, cols. 9-906: 115-118. 
dit, priusquam novi aliquid fieret, anticipare hominem nece, quam postmodum turbatis rebus seram paenitudinem gerere. ex sola igitur suspicione Herodis vinctus in castellum Macherunta abducitur Iohannes ibique obtruncatur.

Hactenus de Iohanne. sed et de salvatore domino in eisdem historiarum suarum libris idem Ioseppus ita scribit.

Fuit autem iisdem temporibus Iesus sapiens vir, si tamen virum eum nominare fas est. erat enim mirabilium operum effector doctorque hominum eorum, qui libenter quae vera sunt audiunt. et multos quidem Iudaeorum. multos etiam ex gentilibus sibi adiunxit. Christus hic erat. hunc accusatione primorum nostrae gentis virorum cum Pilatus in crucem agendum esse decrevisset, non deseruerunt hi qui ab initio eum dilexerant. apparuit enim eis tertio die iterum vivus, secundum quod divinitus inspirati prophetae vel haec vel alia de eo innumera miracula futura esse praedixerant. sed et in hodiernum Christianorum. qui ab ipso nuncupati sunt, et nomen perseverat et genus ${ }^{22}$.

Así pues, por lo que respecta al conocimiento del autor de la Pharetra de las obras de Flavio, este procede en su totalidad de las latinas traducciones de Rufino de Aquilea, si bien nuestro autor resumió el contenido que le convenía mejor y adaptó el texto a su obra de controversia antijudía.

\subsection{Talmud}

En el último capítulo de la Pharetra titulado De mutatione legis veteris in novam ${ }^{23}$ encontramos un pasaje que no proviene ni de San Isidoro, ni de Josefo ni es una cita bíblica, sino que, como identifica el propio texto, proviene del Talmud:

22 Eusebius, Die Kirchengeschichte, ed. Eduard Schwartz y Theodor Mommsen (Leipzig: J. C. Hinrich, 1903) vol. 2:1, págs. 77-81. Traducción inglesa en RuFINus of Aquileia, History of the Church, trad. Philip R. Amidon (Washington, D.C.: The Catholic University of America Press, 2016) págs. 56-57.

${ }^{23}$ Por temática corresponde, como ya hemos apuntado en la tabla de los capítulos correlacionados, al capítulo Quod, Veteri Testamento evacuato, Novum futurum erat (II, 14) del De fide catholica de san Isidoro; $c f$. Isidorus HisPalensis, «De fide catholica contra iudaeos», cols. 520-522. Sin embargo, el contenido de ambos, de nuevo, no es el mismo, teniendo como única coincidencia la cita a Jeremías 31, 31-33. 
Tunc enim docebunt se mutuo, unde legitur in Talmud, in cezer Nassym, id est in secundo: «ibunt de virtute in virtutem» [Ps 83:8 -LXX-]. Ibi dicit rabbi Levi: Non est quies sapientibus in futuro saeculo.

Por primera y última vez, la Pharetra nos ofrece una fuente judía extrabíblica, tal como harían los polemistas cristianos adscritos al tercer patrón de la controversia antijudía de Funkenstein ${ }^{24}$, que consistía en aquellos tratados de polémica que utilizaban la ley oral para denostar el judaísmo. En esta sección el autor está citando el siguiente pasaje talmúdico:

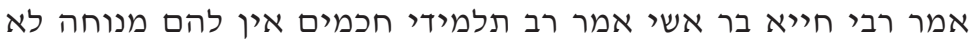

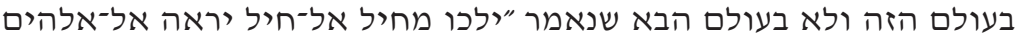

בציון״ בעולי

Se trata de Berajot 64a, lo cual ya pone en evidencia el primer error que nos ofrece la Pharetra: No pertenece al seder Našim como dice, sino al seder Zera 'im. El segundo error, si lo comparamos al texto hebreo canónico, es en cuanto al nombre del rabino: La Pharetra nos dice que esta sentencia la pronunció rabbi Levi, mientras que en la edición de Schottenstein aparece rabi Hiyya bar Aši.

Esta referencia extraña parece desubicada, pues la Pharetra fidei, como hemos visto hasta ahora, solo utilizaba fuentes latinas. Además, la primera obra latina que contiene este pasaje talmúdico, las Extractiones de Talmud (1245), nos lo muestra con una textualidad diferente:

Sapientes magistri non habebunt requiem in futuro saeculo, sicut scriptum est: «ibunt de exercitu in exercitum» [Ps 83:8 -s. hebr.-] -littera nostra: «de virtute in virtutem»- [Ps 83:8 -iuxta LXX- ${ }^{26}$.

En este sentido, este caso aislado podría provenir de la obra que en la mayoría de ocasiones la acompaña y es la segunda parte del compendio de la Pharetra, es decir los Errores iudaeorum.

${ }^{24}$ Funkenstein, «Basic Types of Christian Anti-Jewish Polemics», págs. 379-381.

25 The Schottenstein Edition. Talmud Bavli. Tractate Berachos (Nueva York: Mesorah Publications, 2012) Ber 64a3.

${ }^{26}$ Extractiones de Talmud per ordinem sequentialem, ed. Ulisse CeCINI y Óscar DE la Cruz Palma (Turnhout: Brepols, 2018) pág. 117. 


\subsubsection{Los Errores iudaeorum y Thibaud de Sézanne}

A diferencia del caso de la Pharetra fidei, la segunda obra del compendio, los Errores Iudaeorum, aún inédita hasta la fecha ${ }^{27}$, ya no pretenden demostrar la legitimidad de la mesianidad de Jesucristo ni la obsolescencia del judaismo a través de pasajes del Antiguo Testamento, sino que, según el tercer patrón de Funkenstein, nos expone los errores del judaísmo a partir de diversos pasajes del Talmud y otras referencias rabínicas ${ }^{28}$.

En muchos manuscritos se nos indica que el autor de los Errores fue el converso dominico Thibaud de Sézanne (Theobaldus de Saxannia) ${ }^{29}$, fraile activo en París a mediados del siglo XIII ${ }^{30}$. Si hemos podido ver que la Pharetra fidei nos muestra como fuente principal la obra de Isidoro de Sevilla del siglo vir y otros autores tardoantiguos, Thibaud toma materiales que aluden al Talmud de autores latinos del XII como es el Dialogus contra Iudaeos de Pedro Alfonso ${ }^{31}$ o de más contemporáneos a él como son los treinta y cinco artículos de Donin del siglo XIII ${ }^{32}$. A

27 Actualmente estamos trabajando en una edición de trabajo de esta obra y un estudio de las fuentes y su relación con la Disputa de París de 1240 y las obras literarias que se produjeron a raíz de este evento: IsAaC LAMPURLANÉs, «The Errores Iudaeorum by friar Thibaud de Sézanne. A Critical Working Edition», Mittellateinisches Jahrbuch 55:3 (2020) en prensa.

28 Véanse algunos ejemplos en Isaac LAMPURLAnÉs, Excerptum de Talmud: Critical Edition and Study, Tesis doctoral (Bellaterra: Universitat Autònoma de Barcelona, 2018) pág. 36.

29 Véase en el manuscrito Múnich, Bayerische Staatsbibliothek, clm 23923, fol. 18r-a, donde nos indica: «Ista sunt excerpta de Erroribus Iudaeorum in Thalmuth quos transtulit frater Theobaldus subprior ordinis praedicatorum». Otros académicos como Gilbert Dahan («Les traductions latines de Thibaud de Sézanne», en Le brûlement $d u$ Talmud à Paris 1242-1244, eds. Gilbert DAHAN y Élie Nicolas [Paris: Les Éditions du Cerf, 1999] págs. 95-120) han apuntado que el converso Thibaud de Sézanne también fue un personaje clave en la redacción de la traducción latina del Talmud conocida como Extractiones de Talmud.

30 Cardelle de Hartmann, «Drei Schriften», pág. 330, y «El Dialogus pro ecclesia contra synagogam», pág. 7.

31 John Tolan, Petrus Alfonsi and His Medieval Readers (Gainesville: University Press of Florida, 1993) págs. 116-117.

32 Alexander Fidora, «The Latin Talmud and its translators: Thibaud de Sézanne vs. Nicholas Donin», Henoc 37:1 (2015) págs. 17-28. 
todo esto, hay que añadir que Thibaud de Sézanne fue un personaje importante e involucrado en lo acaecido en torno a la Disputa de París contra el Talmud (1240-1248), figurando su nombre en la última condena de la Ley Oral judía de $1248^{33}$ y, por lo cual, además de sus fuentes latinas, pudo también aprovechar algunos pasajes talmúdicos que se debatieron durante el proceso de la Disputa ${ }^{34}$.

En cuanto al contenido de la obra y la conexión del autor y el contexto de la Disputa, Thibaud de Sézanne, en la parte inicial de los Errores, nos revela que la fuente que utiliza para exponer los errores del judaísmo es el Talmud, al cual -según dice- los judíos le dan más autoridad que a la misma Biblia:

Thalmuth est doctrina et dividitur in quattuor libros quorum quilibet appellatur zezer ${ }^{35}$ in genere ut nos omnes libros vocamus Bibliam. Item quilibet liber (habet) nomen speciale: Primus vocatur Mohes, id est 'Terminus'; secundus Nasym, id est 'Mulieres'; tertius Cassassym, id est 'Sanctuaria'; quartus Yessuhot, id est 'Salvationes'. Hunc Thalmuth iudaei praeferunt libris ${ }^{36}$ Moysi et prophetis et ut magis credendum Thalmuth fabulis addunt fabulas ${ }^{37}$.

Por tanto, en el decurso de los Errores Thibaud expone varios pasajes que presuntamente provienen del Talmud y, sucesivamente, los rebate.

Por consiguiente, no es extraño encontrar en una obra como la Pharetra, una obra Adversus Iudaeos centrada en la refutación del judaísmo a través de la argumentación cristológica del Antiguo Testamento, un pasaje del Talmud que, por la larga tradición de circular junto a los Errores, juzgamos como interpolación de la otra obra del compendio, donde dicho pasaje concuerda mejor tanto por temática como por estructura, que se añadió en un estadio posterior a la redacción originaria de la Pharetra, ya sea por intervención intencionada o por error de copista.

33 Heinrich Denifle y Emile Chatelaine, Chartularium Universitatis Parisiensis, Volume One (Paris: Ex typis fratrum Delalain, 1889) págs. 209-211.

34 LampurlanÉs, Excerptum de Talmud, pág. 36.

35 En hebreo סָדִ 'orden'.

${ }^{36}$ Este libris es una corrección del libros que leemos en el manuscrito, por el sentido de la oración.

37 Múnich, Bayerische Staatsbibliothek, clm. 23923, fol. 18ra. 


\section{COnClusiones}

Por medio de la exposición de las diferentes fuentes y su desarrollo en la Pharetra fidei contra iudaeos y, sobre todo, por la edición que sigue, en este artículo presentamos por primera vez ciertos detalles de esta difundida obra medieval de controversia antijudía, así como también una edición a partir de tres manuscritos.

Concluimos a partir de lo expuesto en el estudio de las fuentes y el enfoque de la Pharetra fidei como de los Errores iudaeorum que las dos obras debieron componerse en contextos diferentes y por manos distintas. Por una parte, los argumentos de la Pharetra fidei se basan en la interpretación cristológica del Antiguo Testamento con la que sustenta la clara llegada del Mesías en la figura de Jesús (la fidei catholicae probatio que encontramos en el prólogo). Los Errores iudaeorum, sin embargo, utilizan la exposición de contenido talmúdico para poner de manifiesto los errores del judaísmo (iudaicorum errorum reprobationem según el prólogo). Asimismo, las fuentes que utilizan una y otra obra también son indicadoras de un origen y redacción independiente: $\mathrm{La}$ Pharetra fidei bebe sustancialmente de obras tardoantiguas o del medievo reciente como son las traducciones latinas de Rufino del Bellum iudaicum y la Historia ecclesiastica y, principalmente, del De fide catholica contra iudaeos de Isidoro de Sevilla; mientras de que los Errores iudaeorum, en la medida en que encontramos pasajes de Pedro Alfonso y Nicolás Donin, son deudores del tiempo que vivió Thibaud de Sézanne en la Disputa de París contra el Talmud y la preocupación del momento por la Ley Oral judía. Por tanto, junto al hecho de que solo encontramos información de autoría en los Errores, nada hace pensar que ambas obras fueran escritas por la misma mano, sino que, como evidencia el prólogo de la Pharetra con la distinción de dos partes "diferentes", dichos tratados fueron reunidos por un compilador ajeno a los autores.

La aparición del pasaje talmúdico de Berajot, dentro de la parte de la Pharetra fidei no resta veracidad a lo antedicho, sino que más bien es un indicio más de la gran popularidad del compendio Pharetra fideiErrores y la gran cantidad de manos copistas que escribieron y trataron estas obras, con sus errores e intervenciones que llegaron a perpetuarse en la tradición hasta hoy. En este sentido, el hecho de encontrar una sola 
mención del Talmud hacia el final de la Pharetra fidei no hace más que evidenciar su intrusión en una obra que trabaja mayoritariamente con argumentos cristológicos del Antiguo Testamento.

\section{Edición DE LA PHARETRA FIDEI CONTRA IUDAEOS}

\subsection{Notas del editor}

\subsubsection{Criterios ortográficos}

Se ha regularizado el texto que ofrecen los manuscritos siguiendo los criterios ortográficos de la edición de la Vulgata de San Jerónimo ${ }^{38}$, debido a la gran cantidad de citas bíblicas presentes en esta obra. No obstante, hemos mantenido la grafía pharetra, mientras que en la Vulgata se escribe con «f», debido a la gran tradición académica y medieval con esta ortografía con respecto al título de la obra/compendio.

\subsubsection{Abreviaturas del aparato crítico}

$$
\begin{array}{ll}
\text { add } .=\text { addidit } & \text { pos. post }=\text { posuit post } \\
\text { iter. }=\text { iteravit } & \text { praem } .=\text { praemisit } \\
m g .=\text { margine } & \text { scl. }=\text { scilicet } \\
\text { om. }=\text { omisit } & \text { transp. }=\text { transposuit }
\end{array}
$$

\subsubsection{Fuentes localizadas y abreviaturas}

En aquellos lugares de la edición donde hemos identificado fuentes literarias, estas vienen indicadas dentro del texto entre paréntesis angulares ([ ] ) con la abreviatura de la obra y la localización del libro en número romano y el párrafo y pasaje en números arábigos. Las obras identificadas con las respectivas abreviaturas son las siguientes:

38 Biblia Sacra iuxta Vulgatam versionem, ed. Robert Weber (Stuttgart: Deutsche Bibelgesellschaft, 1984). 
Ant. $=$ Flavius Iosephus, Antiquitates Iudaicae

Bell. $=$ Flavius Iosephus, Bellum Iudaicum

Hisp. = Isidorus Hispalensis, De fide catholica contra iudaeos

Hor. $=$ Horatius, Ars poetica

En cuanto a las citas bíblicas identificadas, además de acotarlas entre paréntesis angulares, vienen indicadas acorde a las abreviaturas de los distintos libros de la Biblia de la edición de la Vulgata antedicha. Para la referencia talmúdica que hemos comentado en el apartado del estudio utilizamos la abreviatura utilizada en la edición de Schottenstein del Talmud de Vilna.

\subsubsection{Códices}

$A$ Múnich, Bayerische Staatsbibliothek. clm. 16061, f. 124v-130r-b. $B$ Múnich, Bayerische Staatsbibliothek. clm. 21573, f. 1r-10v. C Múnich, Bayerische Staatsbibliothek. clm. 14722, f. 36r-43r.

\subsection{Edición}

\section{[A 124va; $B$ 1r; $C$ 36r] Incipit prologus in Pharetra fidei contra iudaeos ${ }^{39}$}

In disputatione contra iudaeos notate triplicem cautelam: Prima est ut in primis disputationibus studeatis eorum errores ${ }^{40}$ reprobare -sicut habetis in secunda parte- tum quia facilius est eorum errores reprobare quam nostrae fidei articulos probationibus declarare, tum quia non proficiunt semina veritatis, nisi prius extirpentur spinae et tribuli falsitatis. Secunda cautela est ut obiectiones quae videntur esse contra nos non tangatis nisi eas iudaeus per se obiecerit, tunc solvite eas sicut ${ }^{41}$ solutas invenitis ${ }^{42}$. Tertia est ut quando pluribus iudaeis praesentibus disputatis omnibus silentium indicatis excepto uno respondente

\footnotetext{
39 Incipit - iudaeos] om. A

40 errores eorum] transp. $C$

${ }^{41}$ eas sicut eas] transp. $C$

42 invenitis] invenietis $A$
} 
donec illo ${ }^{43}$ superato accedat alius responsurus, ne forte clamoribus vos obruant et etiam ${ }^{44}$ uno loquente alius interim evasionis diverticula studeat invenire.

\section{Incipit Pharetra fidei contra iudaeos}

Tolle arma tua pharetram et arcum [cf. Gn 27:3] ad vulnerandas ${ }^{45}$ vulpeculas quae demoliuntur vineas nostras et accipe gladium spiritus quod est verbum Dei ut testimoniis legis et prophetarum superbus Goliath -id est populus iudaeorum- tamquam ${ }^{46}$ proprio gladio superatur. Distinguitur autem hoc opusculum $^{47}$ in duas partes: In prima ponuntur ${ }^{48}$ quae pertinent ad fidei catholicae probationem. In secunda parte quae pertinent ad iudaicorum errorum reprobationem. [C 36v]

\section{De adventu Christi ${ }^{49}$}

De adventu Christi prophetavit Moyses in Adabarym -id est in Deuteronomio- decimo octavo ${ }^{50}$ capitulo: «prophetam de gente tua et de fratribus tuis sicut me suscitabit tibi Dominus Deus tuus ipsum au[A 124vb]dies» [Dt 18:15]. Et paulo post dicit Moyses: «Dominus ait mihi prophetam suscitabo eis de medio fratrum suorum similem tui et ponam verba mea in ore eius loqueturque ad eos omnia quae praecepero ${ }^{51}$ illi qui autem verba eius quae loquetur in nomine meo audire noluerit ego ultor existam» [Dt 18:17-19]. Hoc non potest intelligi de Iosue qui fuit successor Moysi et dux populi, quia ille non fuit propheta vel quid prophetavit? [ $B$ 1v] Nec fuit similis Moysi, quia dicitur numeri vigesimo septimo ${ }^{52}$ : «tolle Iosue virum in quo ${ }^{53}$ est spiritus Dei» [Nm 27:18] «et dabis ei praecepta cunctis videntibus et partem gloriae tuae» [Nm 27:20], ergo non totam, ergo non fuit ei similis. Neque ullus prophetarum dedit legem nisi Moyses et Christus et ideo dixit: «prophetam sicut me susci-

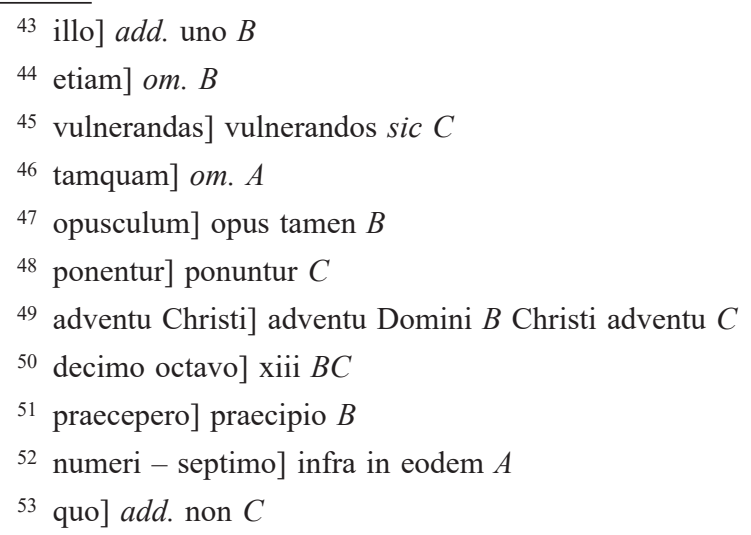


tabit tibi ${ }^{54}$ Dominus ipsum audies» [Dt 18:15], id est sicut audis legem meam sic audi legem suam, quia dicit Dominus deuteronomii decimo octavo ${ }^{55}$ «qui verba eius quae loquetur in nomine meo audire noluerit ego ultor existam» [Dt 18:19]. Nonne hoc ${ }^{56}$ completum est in iudaeis sicut patet in excidio Hierusalem per Titum et Vespasianum ${ }^{57}$ in dispersione gentis eorum per mundum? De hac ultione praedixit ${ }^{58}$ Danihel capitulo ${ }^{59}$ nono: «occidetur Christus et non erit populus eius qui eum negaturus est et civitatem et sanctuarium dissipabit populus -scilicet ${ }^{60}$ Romanus- cum duce venturo -id est cum Tito-» [Dn 9:26].

\section{Quod Christus iam dudum venerit}

Quod autem Christus ${ }^{61}$ iam $^{62}$ venerit probatur per verba Iacob qui ait genesi penultimo capitulo: «non auferetur sceptrum de domo ${ }^{63}$ Iuda et dux de femoribus ${ }^{64}$ eius donec veniat qui mittendus est et ipse ${ }^{65}$ erit expectatio gentium» [Gn 49:10]. Certum est usque ad ortum Christi regem populi non defuisse ex genere Iuda [ $A$ 125ra] usque ad Herodem qui fuit alienigena. Sub quo Christus natus est ${ }^{66}$ qui est «expectatio gentium» [Gn 49:10]. Iudaei autem mentiuntur Christum adhuc non venisse et nescio quem regem de tribu Iuda in extremis orientis partibus regnum tenere. Sed eorum mendatium de facili confutatur, quia sicut nullum templum ${ }^{67}$, nullum altare, nullum sacrificium, ita nullus rex, nullus sacerdos summus remansit eis et quod deterius est ${ }^{68}$ expulsi sunt de regno populo. Neque enim mendax est propheta Oseae qui ait tertio capitulo ${ }^{69}$ : «se-

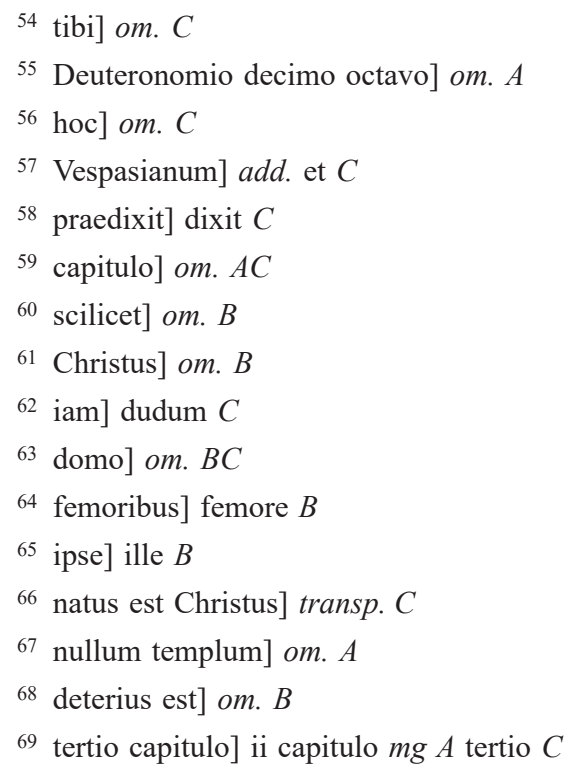


debunt filii Israhel sine rege sine principe $^{70}$ sine sacrificio ${ }^{71}$ sine altari sine ephod $^{72}$ 》 [Os 3:4] quae omnia quis non videt in ipsis nunc esse ${ }^{73}$ completa [Hisp. I, 8]. Obiectio iudaei ${ }^{74}$. Sed obiecit iudaeus: Si Messias ${ }^{75}$ iam $^{76}$ venit, quomodo vel quando completa sunt quae de adventu ipsius ${ }^{77}$ praedixit Isaias undecimo: «egre[B 2r] dietur virga» [Is 11:1] et infra «habitabit lupus cum agno ${ }^{78}$ et pardus cum hedo accubabit ${ }^{79}$ vitulus et leo et ovis ${ }^{80}$ simul morabuntur» [Is 11:6] et cetera. Et iterum: "conflabunt gladios suos in vomeres et lanceas suas in falces non levabit gens [C 37r] contra gentem gladium nec ultra exercebuntur ${ }^{81}$ ad proelium $\left.{ }^{82}\right\rangle$ [Is 2:4] ${ }^{83}$ ? Solutio: Ad quod dicendum est quod per bestias crudeles intelliguntur homines crudeles et iniusti ${ }^{84}$, per animalia simplicia et mansueta homines boni et iusti quos simul pacem Christus habere praecepit. Quod autem de hominibus intelligi voluit ${ }^{85}$ propheta declarat cum addidit quia repleta est terra ${ }^{86}$ Domini. Neque enim ${ }^{87}$ hoc propter $^{88}$ pecudes dixit, quia scientiam et cognitionem Domini habere non possunt. Quod autem alibi dicit: «non exercebuntur ultra ad proelium» [Is 2:4] et cetera. Hae tempore Christi completa sunt in gente in qua natus est. Obiectio iudaeorum contra adventum

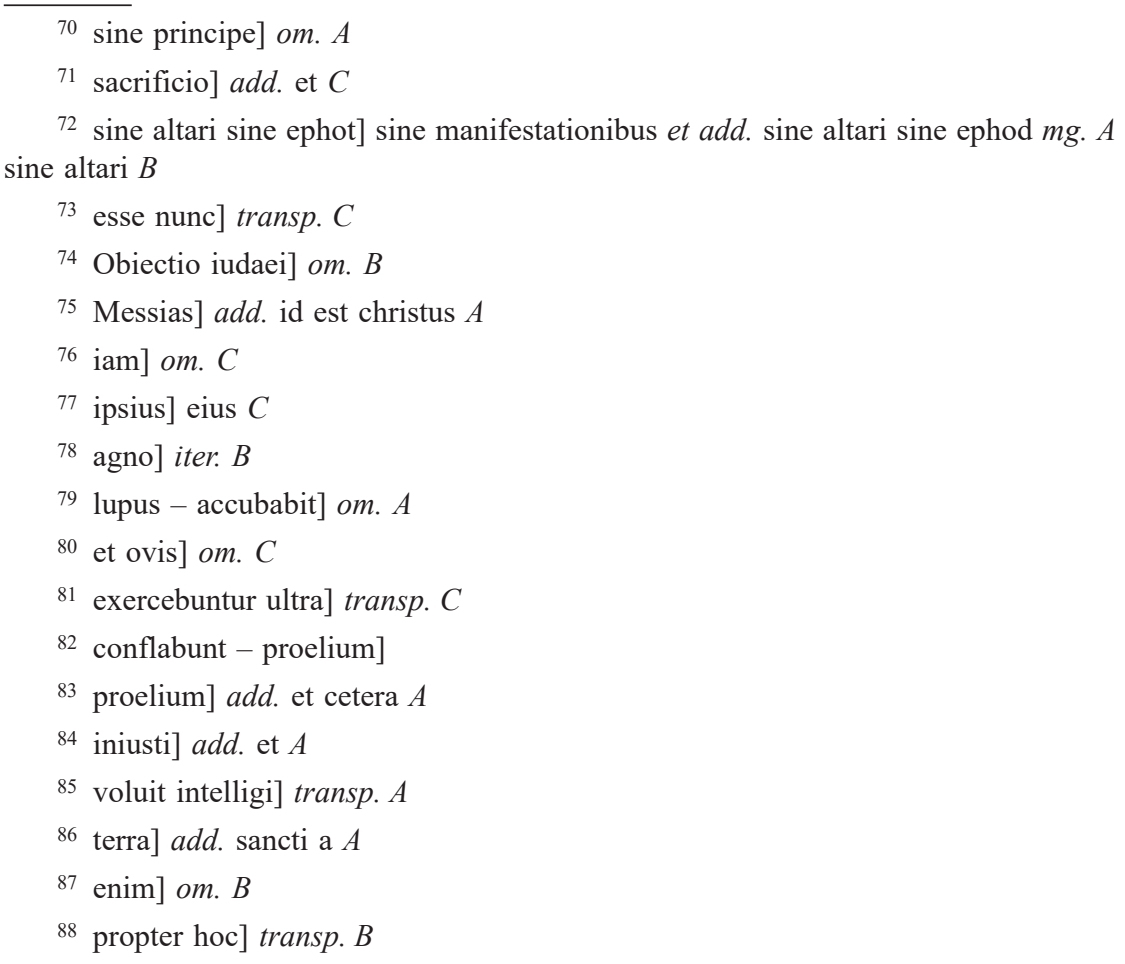


Christi ${ }^{89}$ : In titulo ubi probatur quod Messias -id est Christus ${ }^{90}$ - iam dudum venerit, iudaei obiciunt nobis quod Dominus promisit per Mala[A 125rb]chiam prophetam prius Heliam se missurum [ $c f$. Mal 4:5], sed nondum ${ }^{91}$ venit Helias, ergo nec Messias. Sed haec obiectio nulla est, quia ${ }^{92}$ iudaei tamquam caeci intelligere volunt ${ }^{93}$ de primo adventu Christi quod dictum est de secundo adventu ad iudicium. Quod autem de secundo adventu ad iudicium dictum sit patet in ${ }^{94}$ ipso textu Malachiae in fine ${ }^{95}$ ubi dicit Dominus: «ecce dies veniet succensa quasi caminus et erunt omnes superbi et omnes facientes impietatem stipula et inflammabit eos ${ }^{96}$ dies veniens ${ }^{97}$ dicit Dominus exercituum quem non derelinquit ${ }^{98}$ eis radicem et germen et orietur vobis timentibus nomen meum sol iustitiae» [Mal 4:1-2]. Et paulo post in eodem ${ }^{99}$ : «ecce ego mittam vobis Heliam prophetam antequam veniat dies Domini magnus et horribilis et convertet cor patrum ad filios et cor filiorum ad patres eorum ne forte veniam et percutiam terram anathemate ${ }^{100} \gg[$ Mal 4:5-6].

\section{Quod de virgine natus est Christus}

Quod autem de virgine natus sit probatur per Isaiam septimo capitulo ${ }^{101}$ : «propter hoc dabit Dominus ipse vobis signum ecce virgo concipi $[B 2 \mathrm{v}]$ et et pariet filium et vocabitur nomen eius Emmanuhel» [Is 7:14]. Isidorus ${ }^{102}$ : Sed hic obicit iudaeus infidelis quod nomen quod ibi posuit ${ }^{103}$, halma, non sonat thula, id est virgo. Halma autem tamen puellam significat [cf. Hisp. I, 10, 3].

\footnotetext{
${ }^{89}$ obiectio - Christi] om. A

90 id est Christus] om. $C$

91 nondum] nec dum $C$

92 quia] om. $B C$

93 volunt] add. hoc $A$

94 in] ex $A C$

95 fine] $a d d$. tertio capitulo $m g$. $A$

96 eos] add. ecce $C$

97 veniens] veniet $C$

98 derelinquit] relinquit $A$

99 in eodem] om. A

100 anathemate] $a d d$. amen $A C$

101 capitulo] om. $A C$

102 Isidorus] om. A

103 posuit] add. scilicet $A C$
} 
Ad hoc respondet ${ }^{104}$ iudaeus fidelis conversus ad fidem ${ }^{105}$ quod talis cavillator est ignarus ${ }^{106}$ virtutis nominum ${ }^{107}$ hebraeorum. Mulier namquam sive iuvenis sit sive vetula quam diu virgo est appellari potest bethula; quam diu autem iuvenis est sive virgo sive corrupta, potest vocari vatha. Halma vero nulla ${ }^{108}$ vocatur $^{109}$ nisi sit iuvenis et virgo. Item cum Isaias praedixerit [A 125va] ad Ahaz septimo ${ }^{110}$ : «pete tibi signum a Domino Deo tuo in profundum inferni sive in excelsum supra» [Is 7:11]. Si postea daret signum quod corrupta pareret, numquid non ridiculum esset $[C 37 \mathrm{v}]$ tamquam qui rem arduam et insolitam promisisset, sed ${ }^{111}$ consuetam $^{112}$ et naturalem exhiberet secundum quod dicitur montes parturiunt ${ }^{113}$ nascetur ridiculus mus [Hor. 139] praeterea ${ }^{114}$ adiunxit propter hoc «dabit Dominus ipse vobis signum ecce virgo concipiet ${ }^{115}$ 》 et cetera. Nullum enim ${ }^{116}$ signum esset si corrupta pareret. Numquid Deus qui fecit ut virga arida floreret et fructum ferret -ut habetur Numeri decimo septimo ${ }^{117}$ non potuit facere ut virgo pareret ${ }^{118}$ ? O iudaee! Deus qui rubum ardentem conservavit incorruptum -ut habetur Exodi tertio ${ }^{119}$ - numquid ${ }^{120}$ virgine parientem non potuit servare incorruptam? Item quod dicitur «et pariet filium et vocabitur nomen eius Emmanuhel»[Is 7:14], non potest intelligi de filio ${ }^{121}$

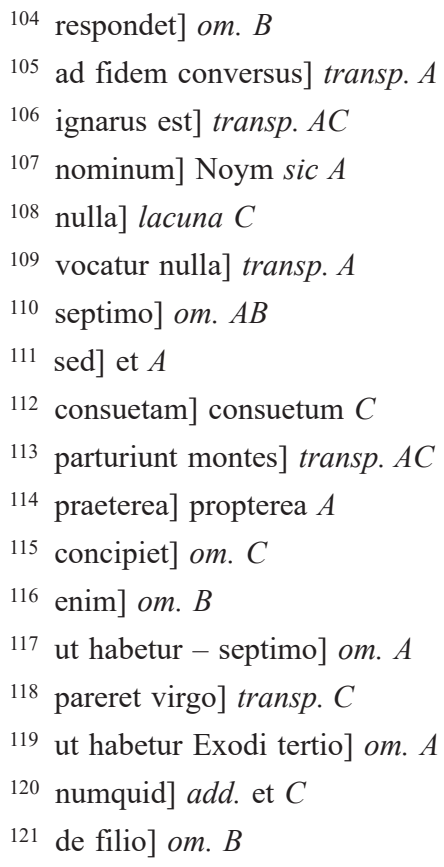


Ahaz - scilicet de quo ${ }^{122}$ Ezechia ${ }^{123}$ - qui tempore huius prophetiae ${ }^{124}$ undecim $^{125}$ annorum erat et viginti quinque annos habuit quando regnare coepit. Nec etiam intelligi potest de filio Isaiae, quia de nullo alio legimus ${ }^{126}$ sive de regibus sive de prophetis ${ }^{127}$ qui dictus sit Emmanuhel. Nec etiam competit filio Isaiae quod ${ }^{128}$ sequitur in octavo capitulo: «et erit extensio alarum eius implens latitudinem terrae tuae o ${ }^{129}$ Emmanuhel» [Is 8:8]. Hic facit propheta exclamationem eius potentiam ammirans cum ait: «0 ${ }^{130}$ Emmanuhel ${ }^{131} »$ [Is 8:8]. Quod autem sequitur «butyrum et mel comedet ut sciat» [Is 7:15] et cetera. Si iudaeus quaerat quomodo intelligatur de Christo, sic expone secundum Isidorum: «Butyrum fructus est ${ }^{132}$ Syna $\left[\begin{array}{ll}B & 3 r\end{array}\right]$ gogae venientis ex circumcisione tamquam bovis sub iugo legis positae. Mel vero ${ }^{133}$ est fructus Ecclesiae venientis ex gentibus cuius fructu -id est opere- $\mathrm{pa}[A 125 \mathrm{vb}]$ scitur Christus». Sequitur: «antequam sciat puer reprobare malum et eligere bonum derelinquatur terra quam tu detestaris a facie duorum regum suorum» [Is 7:16]; et infra, octavo capitulo, sequitur: «antequam sciat puer ${ }^{134}$ vocare patrem suum et matrem suam auferetur fortitudo Damasci» [Is 8:4]. Sic expone: antequam sciat scientia creata vel scientia humana in qua cum aetate proficiebat. Vel secundum Isidorum, sic expone: «antequam sciat -id est antequam ${ }^{135}$ scire faciat secundum divinitatem-Deum se habere patrem et secundum humanitatem virginem se habere matrem iuxta illud quod ait Dominus ${ }^{136}$ ad Abraham cum volebat inmolare filium: «nunc cognovi quod timeas Dominum», [Gn 22:12] id est nunc te cognoscere faciam. [Hisp. I, $10,4]$.

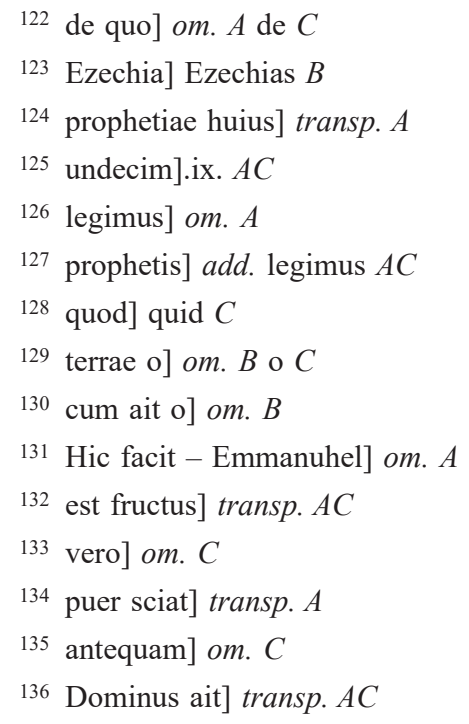




\section{Quod ${ }^{137}$ sit Deus et homo}

Quod autem iste puer sit Deus et homo testatur Isaias capitulo ${ }^{138}$ nono: «parvulus enim natus est nobis et filius datus est nobis et factus est principatus eius super humerum [C 38r] eius -id est crux quam ${ }^{139}$ humeris portavit. Alii autem reges signum principatus sui, scilicet coronam in capite portant- et vocabitur nomen eius Admirabilis -scilicet, in nativitate qua de virgine mirabiliter natus est- consiliarius -in praedicatione- Deus -in miraculorum operatione et peccatorum remissione vel reconciliatione ${ }^{140}$, quia nullus potest dimittere peccata nisi solus Deus- fortis -in passione id est ${ }^{141}$ in diaboli expugnatione-» [Is 9:6]. Psalmus: «Dominus fortis ${ }^{142}$ et potens Dominus potens in proelio» [Ps 23:8]. «Pater futuri saeculi ${ }^{143}$-in resurrectione- princeps pacis -in aeterna beatitudine- multiplicabitur eius imperium et pacis non erit finis super ${ }^{144}$ solium David et super regnum eius sedebit -id est super ecclesiamquae figuratur per solium [A 126ra] David-, ut confirmet illud ${ }^{145}$ in iudicio et ${ }^{146}$ iustitia amodo et usque in sempiternum» [Is 9:6-7]. Haec omnia de nullo rege ${ }^{147}$ nec propheta ${ }^{148}$ possunt intelligi nisi de Christo.

Item Ieremiae trigesimo primo: «creavit Dominus novum ${ }^{149}$ super terram femina circumdabit virum» [Ier 31:22]. Quomodo circumdabit? Si iudaeus $[B 3 \mathrm{v}]$ dicat amplexibus bracchiorum, hoc non est novum ${ }^{150}$, sed circumdabit gremio uteri sui virum qui, licet puer sit ${ }^{151}$ aetate et quantitate corporis, est tamen vir perfectione sapientiae et robore divinitatis. Item Danihel septimo

\footnotetext{
137 Quod] add. Christus $A C$

138 capitulo] om. $A C$

139 quam] add. in $A$

140 remissione vel] om. $A$

141 id est] et $A$

142 fortis] iter. $C$

143 saeculi] $a d d$. saeculi $B$

144 super] $a d d$. super $m g$. $B$

145 illud] om. $C$

146 et] add. in $C$

147 rege] regum $A$

148 propheta] prophetarum $A C$

149 novum] nivim sic $C$

150 novum] verum $C$

151 sit puer] transp. A
} 
capitulo: «postquam vidit Danihel quattuor bestias ascendentes de mari» $[c f$. Dn 7:2-3]. Paulo post adiunxit: «aspiciebam in visione ${ }^{152}$ noctis et ecce cum nubibus caeli quasi filius hominis veniebat ${ }^{153}$ et usque ad antiquum dierum pervenit» [Dn 7:13], id est miraculorum operatione patri ${ }^{154}$ coaequalis apparuit. Sequitur: «et in conspectu eius obtulerunt eum -Glossa: in cruce- et dedit ei potestatem et honorem et regnum et omnes populi tribus et linguae ipsi servient» [Dn 7:1314], id est de omnibus tribubus et populis multi. Et est ${ }^{155}$ simile cum dicitur: omnis homo spirat, tamen non ${ }^{156}$ sequitur quod manus eius et pedes spirent. Sequitur: «potestas eius potestas aeterna quae non auferetur et regnum eius quod non corrumpetur» [Dn 7:14]. Angelus autem hanc revelationem Danhieli ${ }^{157}$ exposuit ${ }^{158}$ dicens: «hae quattuor bestiae magnae quattuor regna sunt quae consurgent de terrasuscipient autem regnum sancti ${ }^{159}$ Dei altissimi et obtinebunt regnum usque in saeculum ${ }^{160}$ saeculorum» [Dn 7:17-18]. Hoc non potest intelligi de regno Messiae cum quo iudaei se sperant regnaturos mille annis, sed de regno Christi nostri cum quo «sancti obtinebunt regnum in saeculum [ $A$ 126rb] saeculorum» [Dn 7:18]. Quaere prius a iudaeo quanto tempore regnaturi sint cum Messia et cum dixerit mille annis tunc conclude quod praedicta non possunt intelligi de regno Messiae ${ }^{161}$.

\section{Quod in Bethlehem natus sit Christus ${ }^{162}$ Deus et homo}

Propheta Micheas ait quinto capitulo: «et tu Bethleem Ephrata parvulus viculus es in milibus Iuda ex te mihi egredietur qui sit dominator in Israhel» [Mi 5:2]. Si egredietur ex Bethleem [ $C$ 38v] et erit dominator in Israhel est homo. Sequitur: «et egressus eius ab initio aeternitatis» [Mi 5:2]. Ex hoc concluditur quod sit Deus. Nihil enim est aeternum, nisi solus ${ }^{163}$ Deus. Quod si

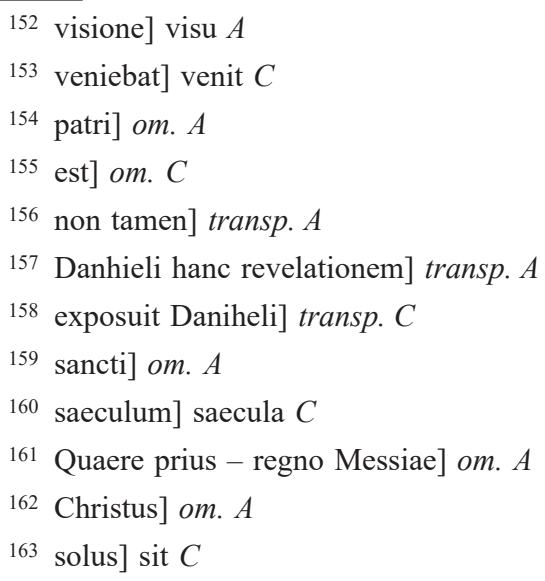


etiam ${ }^{164}$ verum esset quod omnes animae [ $\left.B 4 \mathrm{r}\right]$ ab initio mundi vel ante saecula creatae essent, ut iudaei fabulantur, nulla tamen ab initio aeternitatis creata est, quia impossibile est quod creatori sit coaeterna creatura propterea nulli dies ${ }^{165}$ sunt ${ }^{166}$ dies aeternitatis temporis dies ${ }^{167}$, incoeperunt ${ }^{168}$ esse et desinunt esse. Dies autem aeternitatis ${ }^{169}$ sunt pater et filius et spiritus sanctus, quia tamen illi tres aeterna claritate lucent. Propterea ${ }^{170}$ si omnes animae ${ }^{171}$ a diebus aeternitatis egressae essent, quare propheta illum solum commendaret? De hoc quod omnibus conveniret aut quid magni dixisset. Hoc de Messia iudaeorum intelligi ${ }^{172}$ non possunt, quia ipsum de paradiso venturum expectant, non de Bethleem.

Item eius ${ }^{173}$ humanitatem et divinitatem satis manifeste innuit David in psalmo septuagesimo primo ${ }^{174}$ : «Deus iudicium tuum regi da et iustitiam tuam filio regis ${ }^{175}$ » [Ps 71:2 - LXX-]. Si Christus est filius regis est homo. Eius divinitas ibi innuitur ${ }^{176}$ : «et adorabunt eum omnes reges terrae ${ }^{177}$ » [Ps 71:11 -LXX-] et cetera, quia solus Deus adorandus est secundum legem Moysi. Hoc etiam innuitur in isto versu: "sit nomen eius benedictum in saecula ${ }^{178}$ ante solem permanet nomen eius» [Ps 71:17 - LXX-]. Quae omnia si iudaei de Salomone vel de alio re[A 126va]ge intelligere volunt ${ }^{179}$ frivola sunt. Quomodo enim convenit ei ante solem permanet nomen eius. Quod si etiam verum esset quod ante solem creata esset anima eius ${ }^{180}$, tamen nomen eius tunc non fuit.

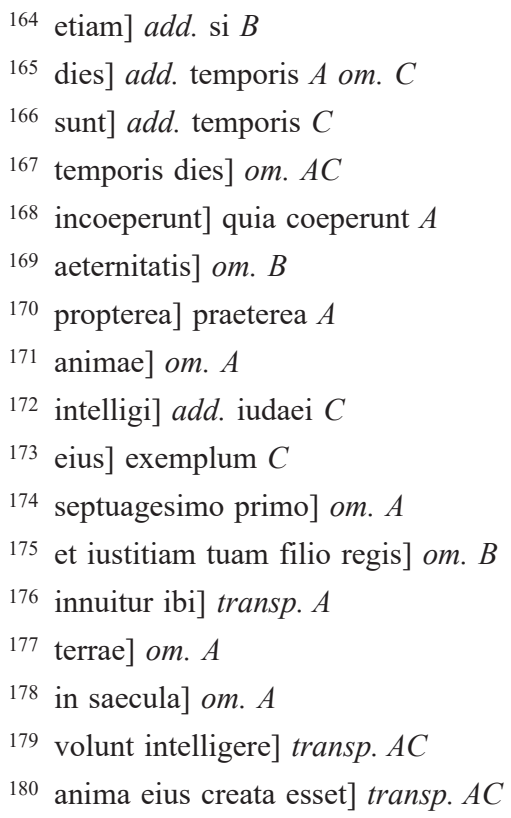


Propterea ${ }^{181}$ quomodo conveniunt Salomoni vel alteri regi: «descendet sicut pluvia in vellus» [Ps 71:6 - LXX-] et cetera. Item «orietur in diebus eius iustitia et abundantia pacis donec auferatur luna» [Ps 71:7-LXX-]. Hoc etiam ${ }^{182}$ de Messia non potest dici ${ }^{183}$ cum quo sperant se regnaturos tamen mille annis. Luna autem numquam auferetur, quia in ultimo die «erit lux ${ }^{184}$ lunae ut lux solis» [Is 30:26] et cetera, ut dicit Isaias trigesimo capitulo ${ }^{185}$.

\section{Quod non oleo corporali, sed paterno spiritu unctus est ${ }^{186}$ in regem et sacerdotem}

David divino afflatus spiritum ad Christum loquitur dicens ${ }^{187}$ psalmo decimo nono ${ }^{188}$ : «sedes tua Deus in saeculum saeculi virga directionis virga regni tui $[B 4 \mathrm{v}]$ dilexisti iustitiam et odisti iniquitatem propterea unxit te Deus Deus tuus oleo laetitiae prae consortibus tuis» $\left[\text { Ps } 44: 7-8-\mathrm{LXX}_{-}\right]^{189}$. In qua prophetia primo David divinitatem Christi ac perpetuitatem demonstrat cum dicit «sedes tua Deus ${ }^{190}$ in saeculum saeculi». Consequenter per aequitatis virgam sceptrum potestatis eius regnumque nuntiat. Postremo quod idem Deus a Deo unctus sit indicat cum dicit ${ }^{191}$ «unxit te oleo laetitiae ${ }^{192}$ Deus Deus tuus» non quidem oleo communi sicut ceteri principes tui-id est principes ${ }^{193}$ qui in signa ${ }^{194}$ praecesserant-, sed oleo laetitiae quo mystice demonstratur spiritus sanctus cuius caelesti infusione et virtute Christus est consecratus ${ }^{195}$ [Hisp. I, 14] in regem et sacerdotem. Psalmus: «tu es sacerdos in aeternum secundum ordinem Melchisedech -qui obtulit panem et vinum [cf. Gn 14:18]- » [Ps 109:4 -LXX-].

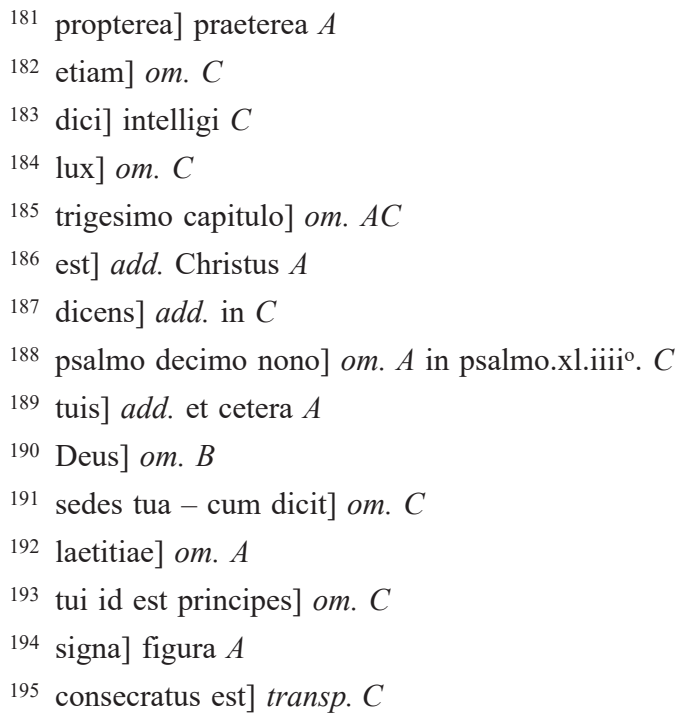




\section{Quod Christus pauper et abiectus venit in mundum ${ }^{196}$ [C $\left.39 \mathrm{r}\right]$}

Dicit ${ }^{197}$ Ieremias decimo quarto $[A$ 126vb] capitulo: «tibi peccavimus expectatio Israhel salvatoreius 198 in tempore tribulationis quare quasi colonus futurus ${ }^{199}$ es in terra et quasi viator declinans ad manendum quare futurus es velut vir vagus et fortis ${ }^{200}$ qui non ${ }^{201}$ potest salvare tu autem in nobis es Domine et nomen tuum super nos invocatum est ne derelinquas nos» [Ier 14:7-9]. Dum enim dicit «tibi peccavimus» exprimit iudaeorum personam ${ }^{202}$ qui in Deum peccaverunt quando venientem eum in forma hominis crucifixerunt. Obtulit enim se aspectibus hominum tamquam vagum et viatorem. Illi autem putantes hoc tamen esse quod videbatur ${ }^{203}$ occiderunt ${ }^{204}$ hominem quasi qui non potest salvare. In hac auctoritatemanifeste exprimitur eius divinitas et humanitas. Ad idem pertinet quod dicit Zacharias propheta nono capitulo ${ }^{205}$ : «iubila filia Hierusalem ecce rex tuus venit ${ }^{206}$ tibi $^{207}$ iustus et salvator ipse pauper et ascendens super asinam et super pullum asinae» [Za 9:9]. Haec omnia non possunt intelligi de Messia iudaeorum quemdicunt cum gloria et divitiis ${ }^{208}$ venturum. Sed quam causam iubilandi habet filia Hierusalem si rex eius veniet pauper vel quomodo potest esse $\operatorname{sal}[B 5 \mathrm{r}]$ vator si pauper est nisi quia licet pauper sit in humanitate habet tamen ${ }^{209}$ virtutem salvandi ex sua divinitate?

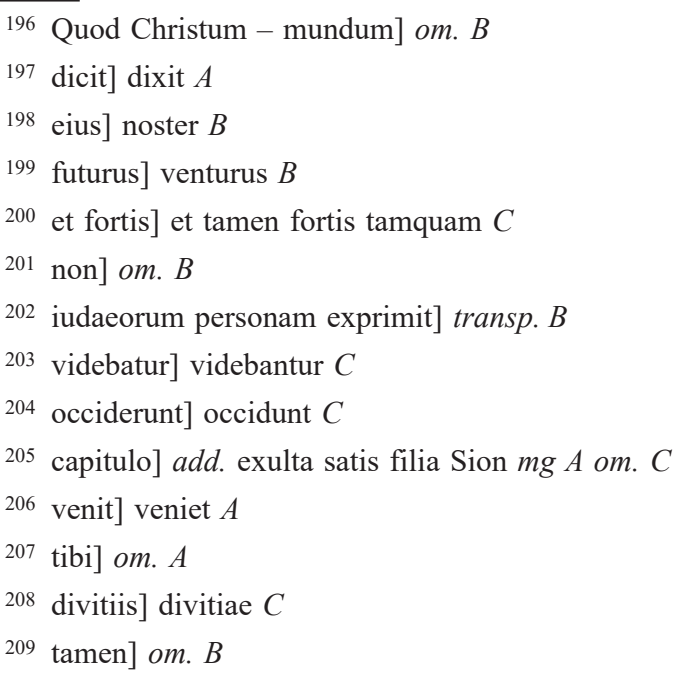




\section{Quod eum non cognoverunt ${ }^{210}$ iudaei $^{211}$}

Propheta Isaias dicit capitulo ${ }^{212}$ primo: «audite caeli et auribus percipe ${ }^{213}$ terra quoniam Dominus locutus est filios enutrivi et exaltavi ipsi autem spreverunt me cognovit bos possessorem suum et asinus praesepe domini sui Israhel autem non cognovit me» [Is 1:2-3]. Hoc etiam praedixit Ieremias capitulo ${ }^{214}$ quinto ${ }^{215}$ : «prae[ $A$ 127ra]varicatione praevaricata est in me domus Israhel et domus Iuda ait Dominus negaverunt me et dixerunt non est ipse» [Ier 5:11-12]. Hoc idem usque nunc iudaei de Christo dicunt non est ipse ${ }^{216}$ expectantes $^{217}$ alium qui est antichristus.

\section{Quod Christus venditus est triginta argenteis ${ }^{218}$}

Quod Christus triginta argenteis venundatus ${ }^{219}$ sit per Zachariam. Ipse ita praenuntiavit dicens undecimo capitulo ${ }^{220}$ : «si bonum est in oculis vestris adferte mercedem meam ${ }^{221}$ et si non quiescite et adpenderunt mercedem meam triginta argenteos ${ }^{222}$ et dixit Dominus ad me proice eos ad statuarium decorum pretium quo adpretiatus sum ab eis et tuli triginta argenteos et proieci $\operatorname{eos}^{223}$ in domum Domini ad statuarium»[Za 11:12-13]. Statuarius est ponderator vel fusor statuarum. Haec causa omnibus nota est. Iudas enim paenitentia ductus pecuniam $^{224}$ reportavit et proiecit in templum et abiit et ${ }^{225}$ laqueo se suspendit

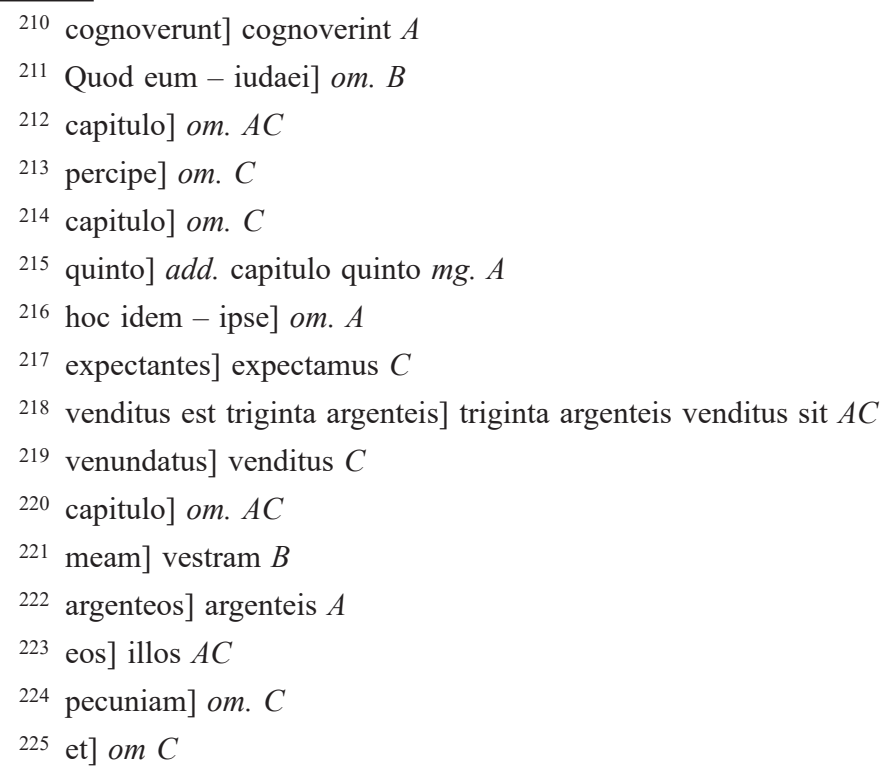


ut impleretur quod dixerat Isaias ${ }^{226}$ : «testis falsus non erit inpunitus» [Prv 19:5] «pro eo quod vendidit argento iustum» [Am 2:6]. Quam pecuniam bene Dominus mercedem suam dixit. Multa enim apud eos opera ${ }^{227}$ fecerat reddens vitam [C 39v] mortuis, lumen caecis, auditum surdis, gressum claudis, pro quibus omnibus nefandi iudaei iniqua aestimatione mortem triginta argenteorum mercedem illi restituerunt [Hisp. I, 20, 2].

\section{Quod iudaei propter invidiam Christum ${ }^{228}$ occiderunt}

Quod iudaei propter invidiam Christum occiderunt probatur ex ${ }^{229}$ libro sapientiae secundo capitulo ${ }^{230}$ ubi dicitur ${ }^{231}$ : «dixerunt impii» [Sap 2:1]; et post in eodem ${ }^{232}$ : «circumveniamus iustum quoniam $[B 5 \mathrm{v}]$ in utili ${ }^{233}$ est nobis et contrarius est operibus nostris et improperat nobis peccata legis» [Sap 2:12] «promittit se scientiam Dei habere et filium Dei se nominat» [Sap 2:13]; et post in eodem ${ }^{234}$ : «si est verus [A 127rb] filius Dei ${ }^{235}$ suscipiet illum de manibus nostris et liberabit eum de manu contrariorum» [Sap 2:18]; et post ${ }^{236}$ : «ut probemus eius patientiam morte turpissima condemnemus eum» [Sap 2:19-20], id est adfixione crucis [Hisp. I, 23, 2].

\section{De gloria Christi et ignominia passionis eius et de scandalo videntium}

De gloria ${ }^{237}$ et ignominia -id est adflictione crucis ${ }^{238}$ - passionis, multa habentur in Isaia quingesimo secundo capitulo: «ecce intelleget servus meus

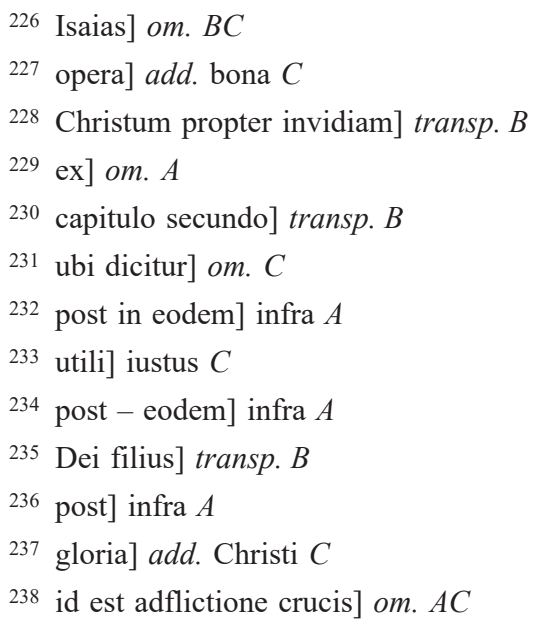


-servus secundum oboedientiam humanitatis- et exaltabitur ${ }^{239}$ et elevabitur et sublimis $^{240}$ erit valde -scilicet in miraculorum ${ }^{241}$ operatione $^{242}$, in resurrectione et ${ }^{243}$ ascensione-sicut obstipuerunt ${ }^{244}$ super eum multi -scilicet quando miracula faciebat- sic inglorius ${ }^{245}$ erit inter viros aspectus eius et forma eius inter filios hominum iste asperget gentes multas -id est lavabit sanguine proprio vel etiam ${ }^{246}$ baptismo- super ipsum continebunt reges os suum» [Is 52:13-15] et cetera. [cf. Hisp. I, 15]

\section{Quod Christus propter peccata nostra ${ }^{247}$ passus est, non sua ${ }^{248}$}

Quod autem propter peccata nostra omnia sustinuerit probatur infra paulo postquinquagesimo tertio capitulo: «vere languores nostros ipse tulit et dolores nostros ipse portavit et nos reputavimus eum quasi leprosum et percussum a Deo et humiliatum ipse autem vulneratus est propter iniquitates nostras» [Is 53:4-5] et cetera. Hoc non potest intelligi de aliquo rege et ${ }^{249}$ propheta nec aliquo puro homine, quia sequitur: «et livore eius sanati sumus» [Is 53:5] [Hisp. I, 15:3].

\section{Quod sponte mortem sustinuit ${ }^{250}$}

Sed quod sponte se ad mortem obtulit ${ }^{251}$ probatur, quia sequitur ${ }^{252}$ : «oblatus est quia ipse voluit et non aperuit os suum» [Is 53:7]. Quod autem iste crucifixus sit Deus et homo probatur cum subditur: «generationem eius quis enarrabit»

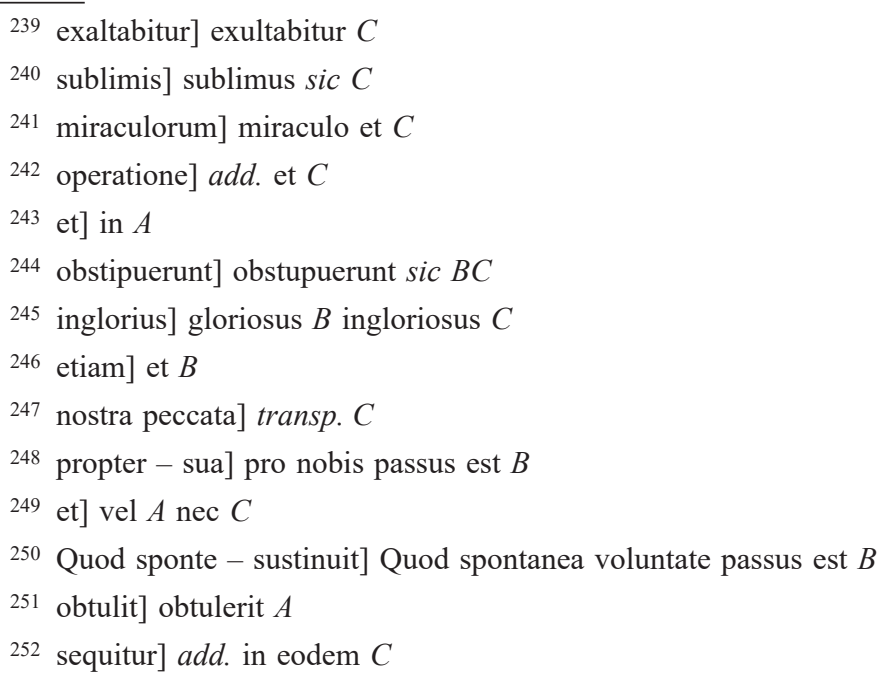


[Is 53:8], [A 127va] quia purorum hominum generatio bene narratur ${ }^{253}$. Sed qualiter Christus secundum divinitatem genitus sit a patre vel secundum humanitatem genitus sit a virgine matre nullus enarrare ${ }^{254}[B 6 \mathrm{r}]$ poterit. Sequitur in eodem ${ }^{255}$ : «vox patris propter scelus populi mei percussi eum et dabit impios pro sepultura et divites pro morte sua eo quod iniquitatem non fecerit neque dolus fuerit in ore eius» [Is 53:8-9]; et paulo post: «ideo dispertiam ei plurimos et fortium dividet spolia» [Is 53:12]. «Dispertia ei plurimos», id est omnes christianos qui in eum credunt ${ }^{256}$ [C 40r]; «et fortium ${ }^{257}$ » id est daemonum, «dividet spolia» id est animas sanctorum a daemonibus raptas liberabit et dividet inter choros angelorum. Haec omnia de Messia non possunt intelligi quia hunc non credunt moriturum.

\section{De genere passionis Christi}

Genus autem ${ }^{258}$ passionis eius ${ }^{259}$ David declarat dicens psalmo vigesimo primo $^{260}$ : «foderunt manus meas et pedes meos» [Ps 21:17 -LXX-] et cetera. Idem: «dederunt in escam meam fel et in ${ }^{261}$ siti mea potaverunt me aceto» [Ps 68:22 - LXX-]. Hae ${ }^{262}$ David non possunt dici ${ }^{263}$ de $^{2} e^{264}$, quia sibi numquam contigerunt.

\section{Quod secundum humanitatem passus est ${ }^{265}$}

Quandocumque loqueris cum iudaeo de passione Dei distingue quod secundum humanitatem passus est qui secundum divinitatem mansit inpassibilis et inmortalis.

\footnotetext{
253 narratur] enarratur $C$

254 enarrare] enarre sic $C$

255 .in eodem] om. A

256 credunt] credent $A$

257 fortium] add. dividet $A$

258 autem] om. $A C$

259 eius] Christi $A$

260 psalmo - primo] om. $A$

261 in] om. $A$

262 hae] add. de $A$

263 possunt dici] dicit $C$

264 dicit de se] possunt dici $A$

265 Quod secundum - est] Notabilem $C$
} 


\section{Quod cum iniquis deputatus est 266267}

Quod etiam inter ${ }^{268}$ latrones suspensus est, Isaias dicit quinquagesimo tertio: «cum sceleratis reputatus ${ }^{269}$ est et ipse peccata ${ }^{270}$ multorum tulit et pro transgressoribus rogavit» [Is 53:12].

\section{Quod per mortem suam nos salvavit ${ }^{271}$}

Quod autem per mortem suam ${ }^{272}$ nos salvavit David innuit in psalmo sexagesimo septimo: «exsurgat Deus noster Deus ${ }^{273}$ salvos faciendi» [Ps 67:21 -LXX-] et cetera ${ }^{274}$. Ibi ponit Isidorus hunc textum contra iudaeos: «Deus noster Deus salvos faciendi ${ }^{275}$ nos et Domini mors et Domini exitus» [Ps 67:21 -LXX-]. «Domini mors» quam sustinuit in cruce et «Domini exitus» de inferno $\operatorname{nos}^{276}$ salvavit. Item Dominus dicit in Oseae decimo tertio capitulo ${ }^{277}$ : «de manu mortis liberabo e $[A 127 \mathrm{vb}]$ os et ${ }^{278}$ de morte redimam eos ero mors tua o mors morsus tuus ero inferne» [Os 13:14]. Item in Zacharia ${ }^{279}$ capitulo $^{280}$ nono: «ecce rex tuus venit tibi iustus et salvator ipse pauper et ascendens $[B 6 \mathrm{v}]$ super asinam» [Za 9:9]. Paulo post pater Simonem dirigirit ad filium dicens: «tu vero in sanguine testamenti tui emisisti vinctos tuos de lacu in quo non est aqua ${ }^{281}$ -refrigerii-> [Za 9:11]. Hoc quaere a iudaeo: Quis umquam sanguinem in tes-

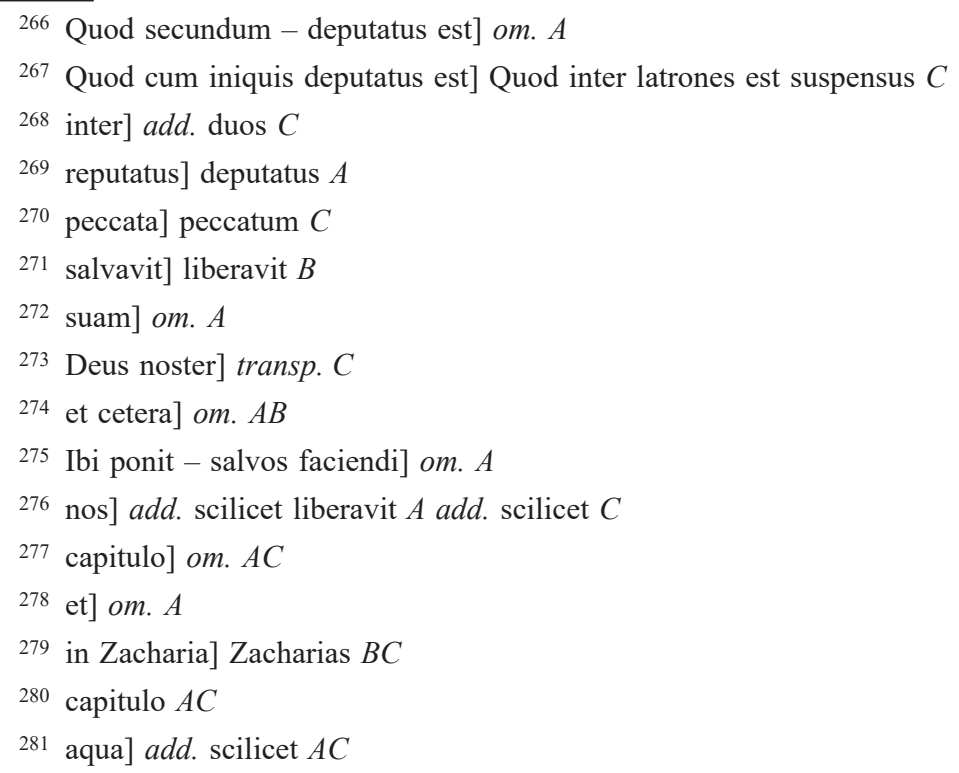


tamento legavit nisi Christus vel quis umquam per sanguinem ${ }^{282}$ vinctos de lacu 283 eduxit praecipue cum sanctissimus prophetarum Ieremias non per sanguinem, sed per funiculos veteribus pannis sub positis sit eductus de lacu in quo non erat aqua, sed lutum in quo iussu regis proiectus fuit ${ }^{284}$ [cf. Ier 38:11].

\section{Quod sepultus fuit et descendit ad inferna ${ }^{285}$}

Isaiae undecimo ${ }^{286}$ : «egredietur virga» [Is 11:1] et cetera. Paulo post sequitur: «non secundum visionem oculorum iudicabit neque secundum auditum aurium arguet ${ }^{287}$ sed iudicabit in iustitia pauperes et arguet in aequitate pro mansuetis terrae et percutiet terram virga oris sui et spiritu labiorum suorum ${ }^{288}$ interficiet impium ${ }^{289} \gg$ [Is 11:3-4]. Ex hiis omnibus probatur eius divinitas. Omnes enim terreni reges iudicant secundum quod vident et audiunt. «Deus autem [C 40v] intuetur cor» [cf. I Sm 16:7] «et spiritu labiorum suorum ${ }^{290}$ interficiet impium» [Is 11:4] quod nullus terrenorum regum facere potest. Et paulo post: «radix Iesse qui stat in signum populorum ipsum gentes deprecabuntur et erit sepulchrum eius gloriosum» [Is 11:10]. In hoc quod dicitur «radix Iesse» notatur eius humanitas. Quod dicitur «ipsum gentes deprecabuntur» notatur eius divinitas, quia [ $A$ 128ra] solus Deus est adorandus ${ }^{291}$. «et erit sepulchrum eius gloriosum» hoc manifestum est: In hebraeo habetur «et erit requies eius gloriosa» et hoc plus importat, quia facta est requies corporis eius gloriosa in sepulchro et requies animae eius gloriosa in inferno et requies utriusque -scilicet corporis et animae- in aeternum ${ }^{292}$ est $^{293}$ in caelo ${ }^{294}$. Requies corporis eius facta

282 per sanguinem] $m g$. $A$

283 de lacu vinctos] transp. A

284 proiectus fuit] est proiectus $A$

285 Quod sepultus - inferna] Quod Deus et homo fuit qui sepultus $A$ Quod Deus et homo fuit qui sepultus est $C$

286 undecimo] ix $A$

287 arguet] iudicabit $A$

288 suorum] om. $A$

289 impium] add. id est antichristum $C$

290 suorum] eius $B C$

291 adorandus est] transp. $C$

292 in aeternum] om. $C$

293 est] add. gloriosa $A$

294 in caelo est] transp. $C$ 
est gloriosa in sepulchro, quia corpus eius ${ }^{295}$ non est corruptum. Unde dicit: «quoniam non derelinques ${ }^{296}$ animam meam ${ }^{297}$ in inferno nec dabis sanctum tuum videre corruptionem» [Ps 15:10-LXX-]. Hoc David de se [B 7r] ipso dicere non potuit, quia David vidit corruptionem. Item facta est requies animae eius gloriosa in inferno, quia solus fuit inter mortuos liber, unde ait in psalmo octogesimo septimo: «vita mea ${ }^{298}$ inferno adpropinquavit ${ }^{299}$ aestimatus sum cum descendentibus in lacum factus sum sicut homo sine adiutorio inter mortuos liber» [Ps 87:4-5 -LXX-]. Descendit enim sicut homo in infernum, sed solus inter mortuos fuit liber ${ }^{300}$, quia mors illum tenere non potuit [Hisp. I, 51, 1]. Fuit etiam requies animae eius gloriosa in inferno, quia lumine ${ }^{301}$ divinitatis suae sanctos suos ibi inluminavit. Unde ipse ait in Ecclesiastico in ${ }^{302}$ libro Iesu filii Sirach ${ }^{303}$ vigesimo quarto capitulo: «penetrabo omnes inferiores partes terrae et inspiciam omnes dormientes et inluminabo omnes sperantes in Domino $^{304}$ » [Sir 24:45]. Et ${ }^{305}$ Isaiae capitulo ${ }^{306}$ nono: «habitantibus in regione umbrae mortis lux orta est eis» [Is 9:2]. Tertio fuit requies eius gloriosa in inferno, quia suos inde eripuit, unde ait Oseae decimo tertio capitulo ${ }^{307}$ : «de manu mortis liberabo eos» [Os 13:14] et cetera. Facta est etiam requies eius gloriosa in caelo Deo patri aeternaliter conregnando, unde psalmus: «dixit Dominus Domino meo sede a $\operatorname{dex}[A$ 128rb]tris meis donec ponam» [Ps 109:1 -LXX-] et cetera. Si iudaeus dicit quod David hoc de Abraham dicit ${ }^{308}$ vel de alio, tunc quaere quomodo ergo sequitur: «tecum principium in die virtutis tuae in splendoribus sanctorum ex utero ${ }^{309}$ ante luciferum genui te» [Ps 109:3 -LXX-]. Et

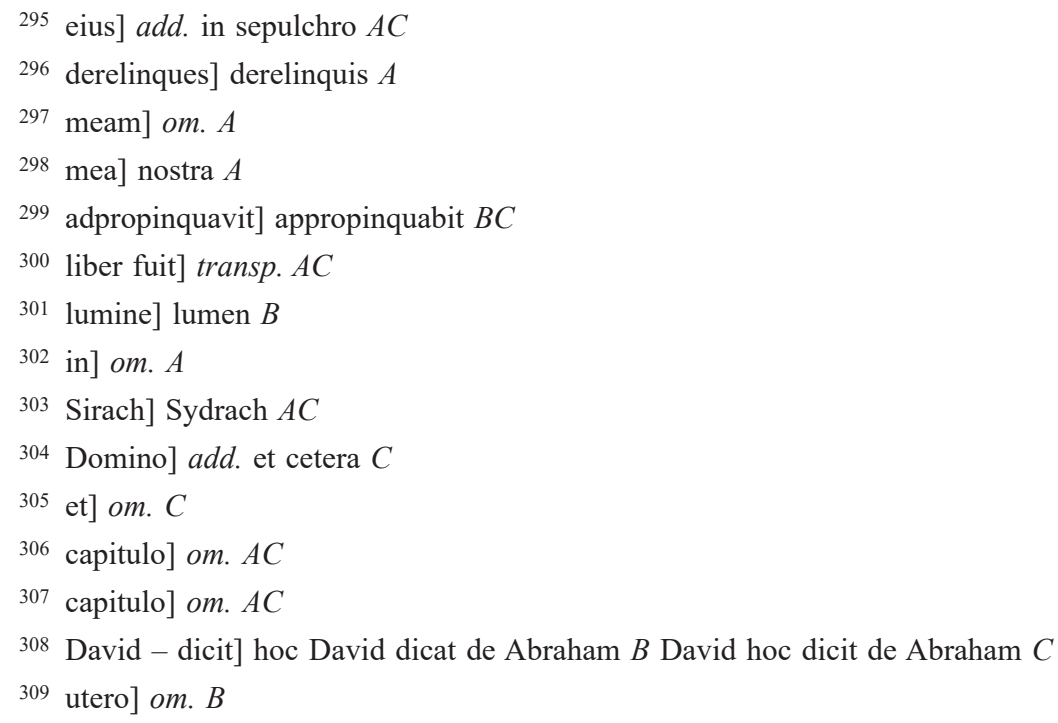


illud: «tu es sacerdos in aeternum secundum ordinem Melchisedech ${ }^{310}$ » $[\mathrm{Ps}$ 109:4 - LXX-]. Abraham enim non fuit sacerdos. Et quis fuit sacerdos secundum ordinem Melchidesech? Nullus.

\section{De resurrectione Christi}

Pater resuscitat filium dicens in Psalmo quinquagesimo sexto ${ }^{311}$ : «exsurge gloria mea exsurge psaltarium et cithara» [Ps 56:9 -LXX-]. Et respondet ipse: «exsurgam diluculo» [Ps 56:9 -LXX-]. Item in psalmo tertio ${ }^{312}$ : «ego dormivi et soporatus sum et exsurrexi» [Ps 3:6-LXX-]. Item in Isaia trigesimo tertio capitulo $^{313}$ : «nunc consurgam dicit Dominus nunc exaltabor nunc elevabor» [Is $33: 10]$.

\section{De ascensione Christi 314315}

De Christi ascensione psalmus decimo octavo ${ }^{316}$ : «asummo caelo egressio eius et occursus eius usque ad $[C 41 \mathrm{r}]$ summum $[B 7 \mathrm{v}]$ eius nec est qui se abscondat a calore eius ${ }^{317} \gg$ [Ps 18:7 -LXX-]. Est calor amoris et calor ${ }^{318}$ spiritus sancti a quo nullus bonorum ${ }^{319}$ se abscondit et est calor iustitiae eius -scilicet ignis infernalis- a quo nullus malorum se abscondet ${ }^{320}$, unde Psalmus, nonagesimo sexto ${ }^{321}$ : «ignis ante ipsum praecedit et inflammabit in circuitu inimicos eius» [Ps 96:3 - LXX-]. Item ${ }^{322}$ psalmus quadragesimo sexto $^{323}$ : «ascendit Deus in iubilo ${ }^{324}$ et Dominus in voce tubae» [Ps 46:6

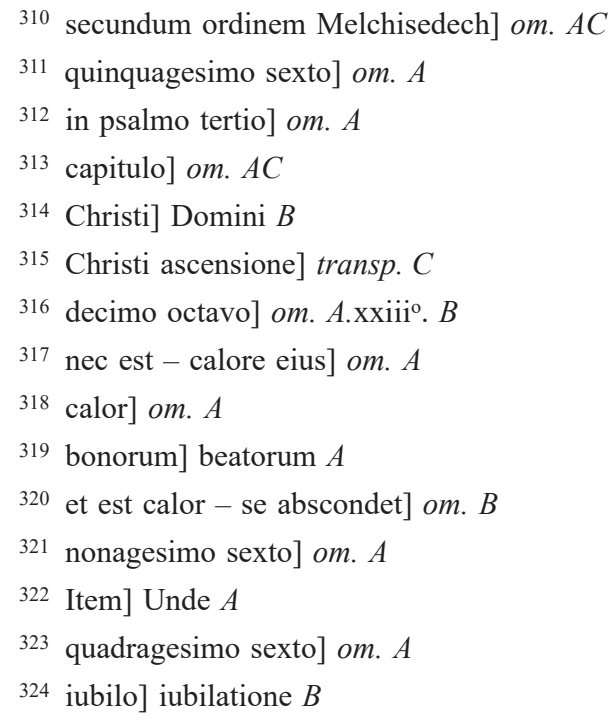


-LXX-]. Quod si hoc ${ }^{325}$ iudaeus non vult de Christo intelligere ${ }^{326}$, quaere quando Deus sic ascenderit ${ }^{327}$ vel unde. Item psalmus sexagesimo sexto ${ }^{328}$ : «regna terrae cantate Deo psallite Domino qui ascendit super caelos ${ }^{329}$ caelorum ad orientem» [Ps 67:33-34 - LXX-] et ${ }^{330}$ bene adiecit ${ }^{331}$ ad orientem, quia idem locus in orientis partibus est ubi Christus resurrexit et inde in ${ }^{332}$ caelum ascendit ut dicit Isidorus [Hisp. I, 56, 5] vel ad orientem id est ad beatitudinem in qua aeterna claritas semper oritur et numquam occidit. Item Amos nono capitulo ${ }^{333}$ : «Dominus Deus exercituum qui tangit terram et tabescet» [Am 9:5]. Et infra in eodem ${ }^{334}$ : «qui aedificat in caelo ascensionem suam et fasciculum suum super terram fundavit» [Am 9:6]. Hoc expone [A $128 \mathrm{va}]$ de missione spiritus sancti, sed Isidorus introducit hunc textum sic: aedificavit ${ }^{335}$ Dominus in caelo ascensum suum et pollicitationem in terra fundavit [Hisp. I, 56, 6]. Item Micheas capitulo ${ }^{336}$ secundo: «ascendet pandens iter ante eos dividet et transibunt portam egredientur per eam -scilicet 337 de mundo ad caelum ${ }^{338}$ - et transibit rex eorum coram eis et Dominus in capite eorum -tamquam princeps ${ }^{339} \rightarrow$ [Mi 2:13]. Item psalmus sexagesimo septimo ${ }^{340}$ : «ascendens in altum captivam duxit captivitatem dedit dona hominibus» [Eph 4:8; cf. Ps 67:19 -LXX-]. Sic Paulus assignat textum Psalmi qui bene novit textum hebraeorum. Hic etiam notatur Christi ascensio et sancti

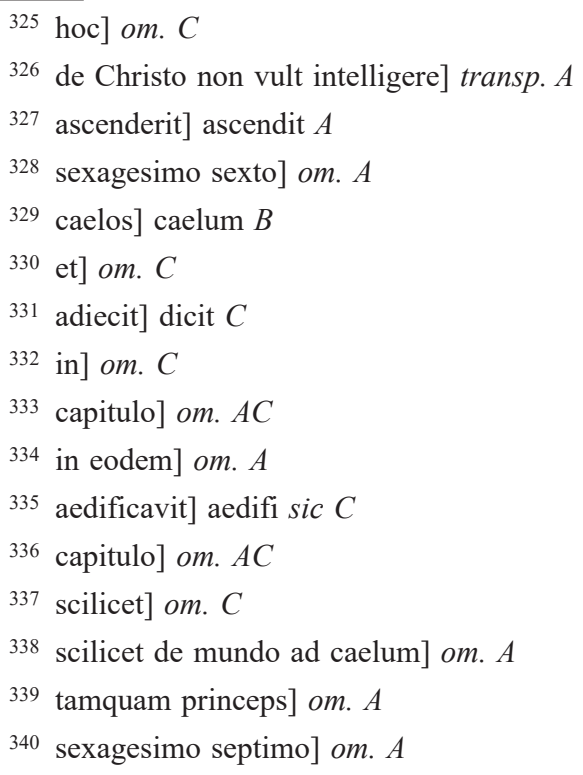


spiritus $^{341}$ missio. Quaere a iudaeo: quomodo dicitur Deus ascendere ad ${ }^{342}$ caelum qui ubique est, sicut Salomon ait tertio Regum ${ }^{343}$ octavo capitulo $^{344}$ : « $\mathrm{Si}^{345}$ caelum et caeli caelorum ${ }^{346}$ te capere non possunt quantomagis domus haec ${ }^{347}$ quam aedificavi tibi» [III $\operatorname{Rg} 8: 27$ ]. Et in propheta: «caelum et terram ego impleo» [Ier 23:24] qui ergo ubique est de loco ad locum moveri non potest. Sed ascensio est motus de $[B$ 8r] loco ad locum ergo Deus ascendere non potest. Motus enim de loco ad locum tamen convenit circumspectibilibus $^{348}$, sed Deus est incircumspectibilis ${ }^{349}$, ergo sibi non convenit. Ascendit ergo Deus in caelum secundum humanitatem qui ubique est per divinitatem.

\section{De missione spiritus sancti in discipulos 350}

De missione spiritus sancti Dominus ait per Iohel capitulo ${ }^{351}$ secundo: «effundam spiritum meum super omnem carnem -id est super multos de omni carne- et prophetabunt filii vestri et filiae vestrae» [Ioel 2:28] et cetera. Et paulo post $^{352}$ : «sed et super ${ }^{353}$ servos meos et super ${ }^{354}$ ancillas in diebus illis effundam spiritum meum» [Ioel 2:29]. $\mathrm{Et}^{355} \mathrm{Zacharias}$ capitulo ${ }^{356}$ duodecimo: «effundam super domum David et super habitantes Hierusalem spiritum gratiae» [Za $12: 10]$.

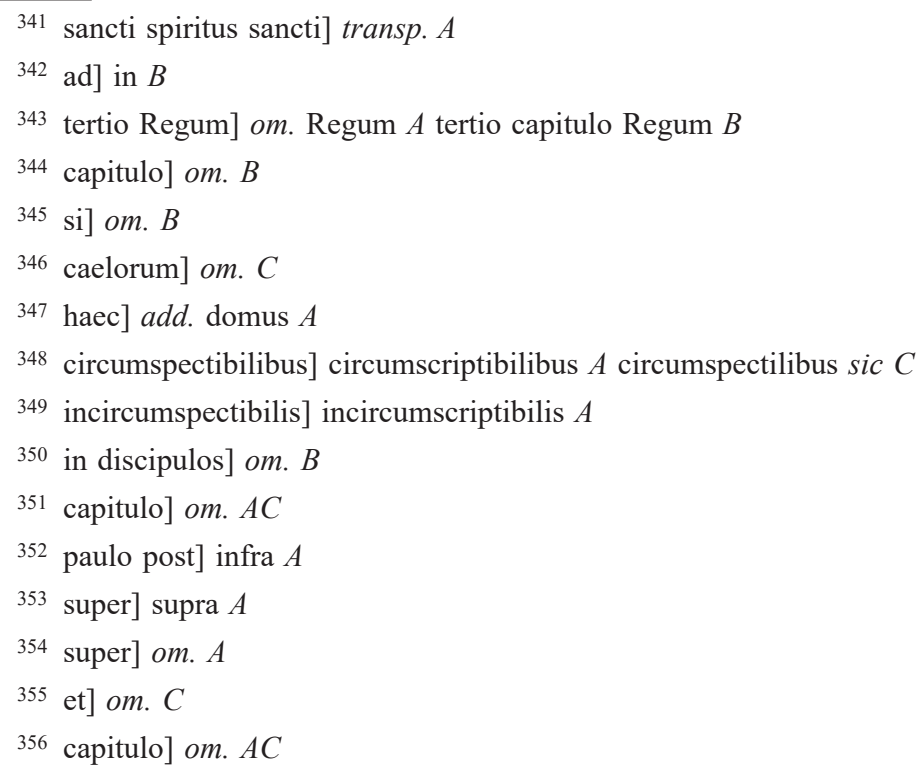




\section{Quod apostoli variis linguis apostoli loquebantur ${ }^{357}$}

Quod variis linguis $[A 128 \mathrm{vb}]$ loquebantur apostoli et per totum mundum praedica[C 41v]verunt testatur David psalmo decimo octavo ${ }^{358}$ : «non sunt loquellae neque sermones quorum - scilicet sermonum ${ }^{359}$ - non audiantur voces eorum» [Ps 18:4 - LXX-] esse, quia loquebantur omnes linguas «in omnem terram exivit sonus eorum» [Ps 18:5 - $\mathrm{LXX}^{-}$] quod de nullis prophetis potest dici, quia non loquebantur omnes linguas nec per totum mundum praedicaverunt, sed maxime ${ }^{360}$ in confinio Iudaeae.

\section{De planctu iudaeorum qui ${ }^{361}$ Christum crucifixerunt $^{362} 363$}

Quod iudaei qui Christum crucifixerunt videbunt eum iudicem venturum ${ }^{364}$. Ipse praedixit per Zachariam duodecimo capitulo ${ }^{365}$ : «aspicient ad me quem confixerunt» et statim propheta submittit ${ }^{366}$ «plangent eum planctu quasi super unigenitum et dolebunt super eum sicut doleri solet in morte primogeniti» [Za 12:10]. Hic planctus etiam ${ }^{367}$ potest referri ad eundem planctum quem multi iudaeorum planxerunt quando Christum resurrexisse et ascendisse audierunt, unde statim sequitur: «in die illa magnus erit ${ }^{368}$ planctus in Hierusalem» [Za 12:11] et cetera.

357 apostoli - loquebantur] apostoli loquantur variis linguis $A$ trans $p$. variis linguis loquebantur apostoli $C$

358 psalmo decimo octavo] om. A

359 scilicet sermonum] pos. post voces eorum $B$

360 maxime] om. $B$

361 qui] super $C$

${ }^{362}$ De planctu - crucifixerunt] Quod iudaei videbunt Christum venientem iudicem super se $B$

363 crucifixerunt] quem occiderunt $C$

364 venturum] add. iuxta quod $A$

365 capitulo] om. $A C$

366 submittit] submisit $B$ subinfert $C$

367 etiam planctus] transp. $B$

368 erit magnus] transp. $C$ 


\section{Quod pro nece ${ }^{369}$ Christi iudaei desolati et dispersi sunt ${ }^{370}$}

Quod pro Christi morte ${ }^{371}$ iudaei desolati ${ }^{372}$ et dispersi sunt ${ }^{373}$ dicit David in ${ }^{374}$ psalmo septuagesimo secundo: «quomodo facti sunt in desolationem subito defecerunt perierunt $\left[\begin{array}{ll}B & 8 \mathrm{v}\end{array}\right]$ propter iniquitatem suam» $\left[\right.$ Ps 72:19 $-\mathrm{LXX}-$ ]. Item $^{375}$ psalmo nonagesimo tertio ${ }^{376}$ «Deus ultionum» [Ps 93:1 -LXX-]; «captabant in animam iusti et sanguinem innocentem condemnabunt ${ }^{377378}{ }$ [Ps [P3:21 -LXX-] «et reddet illis iniquitatem ipsorum et in malitia eorum ${ }^{379}$ disperdet eos ${ }^{380}$ disperdet illos Dominus Deus noster» [Ps 93:23 - LXX-]. Bis dicit disperdet, quia dispersit in mundum et disperdet in infernum ${ }^{381}$. Item Danihel nono capitulo ${ }^{382}$ : «occidetur christus et non erit eius - populus ${ }^{383}$ qui eum negaturus est- et [A 129ra] civitatem et sanctuarium dissipabit populus cum duce venturo -id est cum Tito-> [Dn 9:26] [cf. Hisp. I, 5, 8]. Qualiter autem civitas Hierusalem propter necem Domini vastata sit ${ }^{384}$ per Titum et Vespasianum scribit Iosephus libro 385 decimo quarto: sub Tito captivata sunt circa quindecim milia. Item quinquaginta ${ }^{386}$ et triginta quinque milia vendita [Bell. III, X, 10]. Item Hierusalem ascendi poterat ${ }^{387}$ congestione cadaverum et ${ }^{388}$ civitas plena cadaveribus [Bell. III, VII, 23],

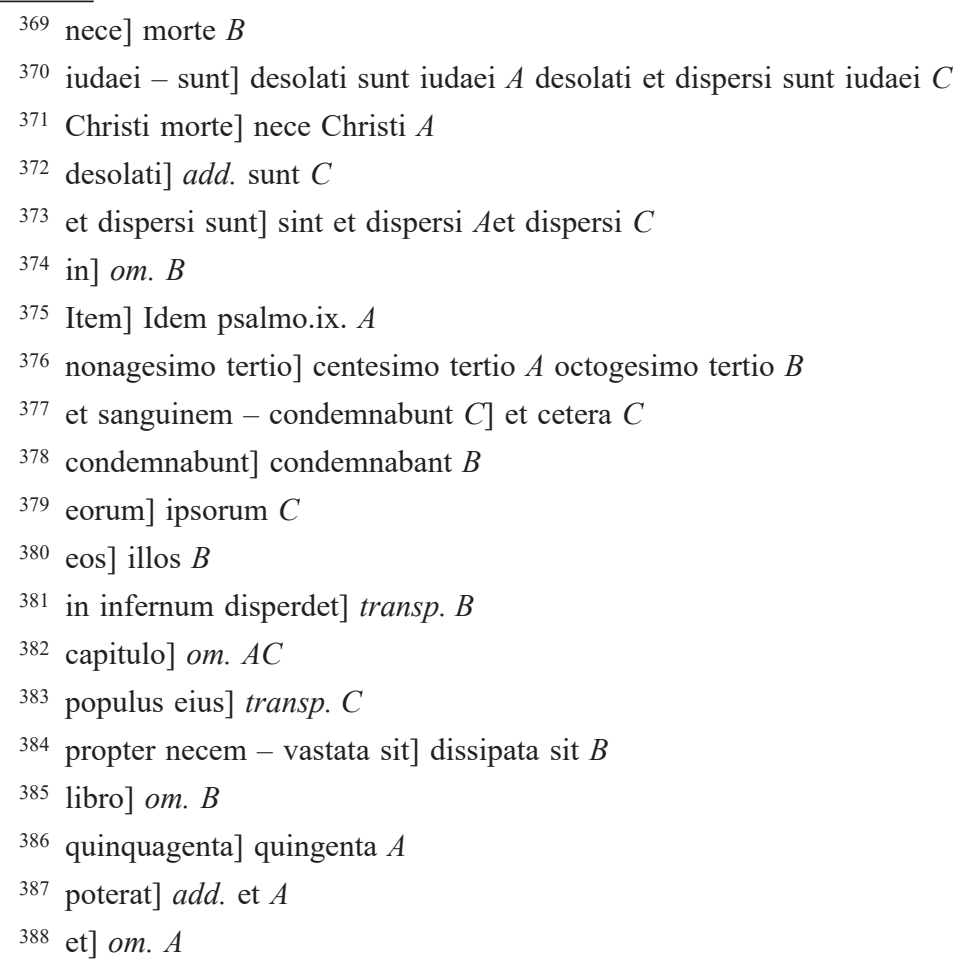


ita quod etiam ${ }^{389}$ viae cadaveribus clauderentur ${ }^{390}$ et ${ }^{391}$ super cadavera iretur [Bell. VI, V, 1]. Item in Iordane infiniti submersi sunt. Item plurium ${ }^{392}$ milium ventres exenterati sunt propter aurum quod glutiverant ${ }^{393}$ [Bell. V, 13, 4]. Item sanguis largior fuit ut ignem extingueret [Bell. VI, V, 1]. Item plura milia se ipsos occiderunt [Bell. VI, V, 2]. Item triginta quinque milia se mutuo occiderunt ${ }^{394}$. Item matres pueros comedebant ${ }^{395}$ [Bell. 6, 3, 4]. Haec Iosephus. Cum igitur iudaei saepe grandia peccata conmiserint ${ }^{396}$, idolatriam et alia multa et ${ }^{397}$ numquam tam acriter puniti fuerint ${ }^{398}$. Patet quod grande sit peccatum quod Christum ${ }^{399}$ crucifixerunt ${ }^{400}$. Item Iosephus libro ${ }^{401}$ decimo octavo: Iacobus frater Iesu tantae fuit sanctitatis ut destructio Hierusalem et calamitas quam passi sunt iudaei per Titum eis acciderit ${ }^{402}$ propter necem Iacobi. Haec Iosephus. Cum autem idem [C42r] Iacobus de pinnaculo templi praecipitatus fuerit pro eo quod Christi gloriam praedicavit et pro ${ }^{403}$ peccato mortis eius Hierusalem sit destructa, ut dicit Iosephus: Patet quod veritatem praedicaverat.

\section{De efficatia ${ }^{404}$ baptismi Christianorum ${ }^{405}$}

Gratiam baptismi Dominus per Ezechielem praedixit trigesimo sexto capitulo ${ }^{406}$ : «cum sanctificatus fuero in vobis» [Ez 36:23] «congregabo vos de

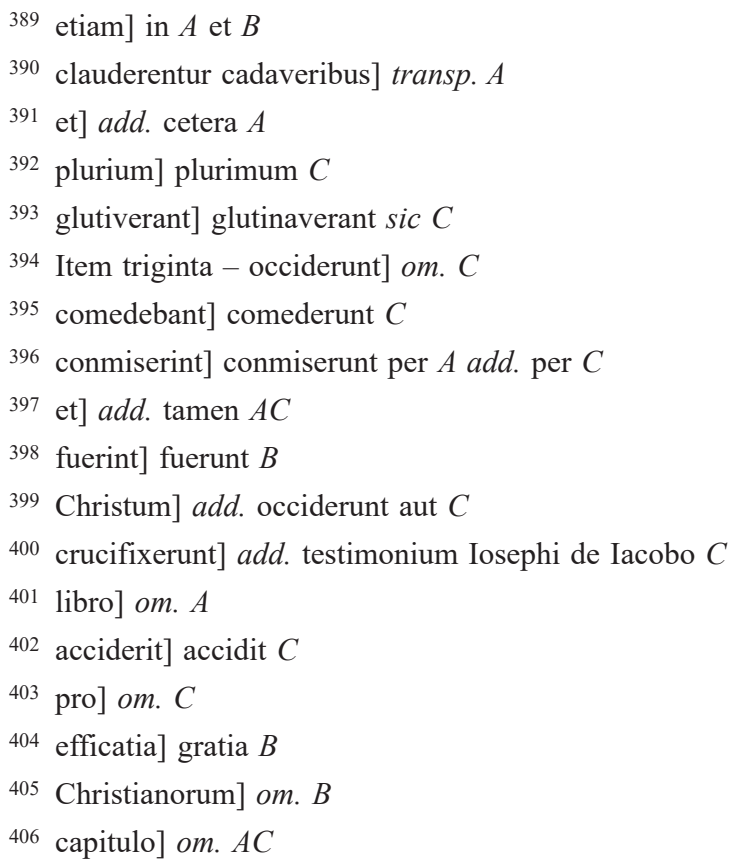


universis $[B$ 9r] terris» [Ez 36:24] «et effundam super vos aquam mundam et mun[ $A$ 129rb]dabimini ab omnibus inquinamentis vestris et ab universis idolis vestris mundabo vos et dabo vobis cor novum et spiritum novum ponam in medio vestri» [Ez 36:25-26] [cf. Hisp. II, 24, 13]. Figura baptismi praecessit in veteri testamento, quia legitur quarto Regum quinto ${ }^{407}$ quod cum Naaman Syrus vir leprosus ex iussu Helysei septies in Iordane baptizatus est ${ }^{408}$ [cf. IV Rg 5:10], ubi ${ }^{409}$ figuratur efficatia baptismi nostri qui primo in Iordane incepit.

\section{Testimonium Iosephi de Iohanne ${ }^{410}$}

Hoc testimonium perhibet Iosephus Iohanni Baptistae dicens libro decimo octavo: Herodis exercitus ideo periit, quia in eum indignatio divina permota est pro vindicta Iohannis qui vocabatur ${ }^{411}$ Baptista. Hunc enim Herodes occidit virum valde bonum qui praecipiebat iudaeis virtuti operam dare, iustitiam colere in Deum pietatem servare. Tunc eum ${ }^{412}$ demum baptismum acceptabilem fore non solum si ad absolvenda ${ }^{413}$ peccata sumatur ${ }^{414}$. Verum etiam ad sanctimoniam corporis ${ }^{415}$ et animae iustitiam purificationemque servetur omniumque pariter $^{416}$ virtutum velut ${ }^{417}$ signaculum et custodia fidelis habeatur. Herodes veritus, ne doctrinae eius persuasione populi a regno eius ${ }^{418}$ discederent $^{419}$, occidit Iohannem. [Ant. XVIII, 5, 2]. Haec Iosephus. Idem Iosephus dicit: Fuit hisdem ${ }^{420}$ temporibus Iesus, vir sapiens, si eum tamen virum ${ }^{421}$ nominare fas est. Erat enim mirabilium operum effector et doctor eorum qui libenter quae vera sunt audiunt et multos iudaeorum et multos ex gentibus sibi adiunxit.

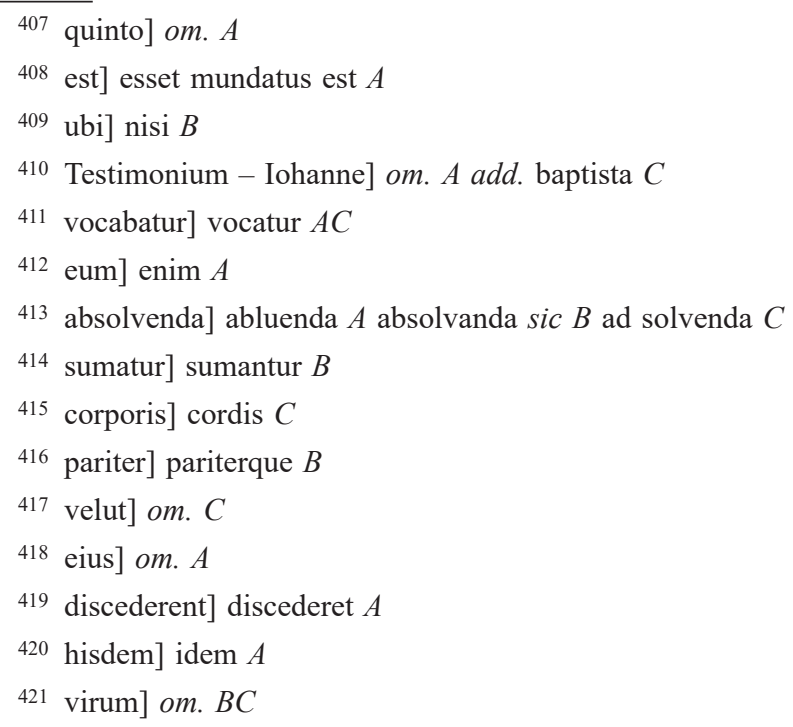


Christus hic erat. Hunc ${ }^{422}$ accusatione ${ }^{423}$ primorum nostrae gentis cum Pilatus in cruce agendum decrevisset, non deserve[ $A$ 129va]runt qui ab initio eum dilexerunt. Apparuit eis iterum vivus, secundum quod prophetae vel haec ${ }^{424}$ vel alia de eo futura praedixerant, sed et ${ }^{425}$ in hodiernum diem Christianorum, qui ab ipso dicti sunt, et nomen perseverat et genus [Ant. XVIII, 3, 3]. [B 9v] Haec Iosephus. Iosephus autenticus est apud iudaeos, sed testimonium de Christo dicunt ibi non esse. Sed tunc ${ }^{426}$ quaere si habeant ${ }^{427}$ ibi de rege Herode, et de Tito et Vespasiano quod si easdem habent historias, habent etiam de Christo nisi tunc eas ${ }^{428}$ sponte deleverint. ${ }^{429}$

\section{De cruce Domini nostri quam iudaei derident ${ }^{430}$}

De cruce Domini nostri Iesu Christi, quam iudaei derident, praedixit Isaias undecimo capitulo ${ }^{431}$ : «levabit Dominus signum in nationibus et congregabit dispersos ${ }^{432}$ Israhel [ $C 42 \mathrm{v}$ ] et profugos Iuda colliget a quattuor plagis terrae» [Is 11:12]. Idem quadragesimo nono: «ecce levabo ad gentes manum meam et exaltabo ad populos signum meum» [Is 49:22]. Item in Ezechieli ${ }^{433}$ decimo septimo ${ }^{434}$ : «exaltavi ${ }^{435}$ lignum humile et siccavi lignum viride et frondere ${ }^{436}$ feci lignum aridum» [Ez 17:24]. Crux Christi praefigurata est multis figuris. Legitur enim in Exodo decimo quinto capitulo ${ }^{437}$ quod cum filii Israhel venis-

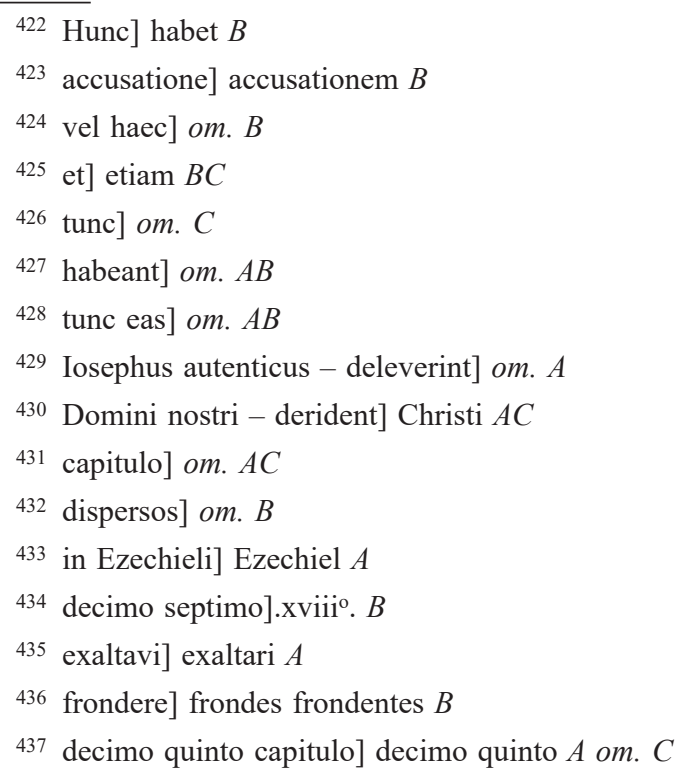


sent $^{438}$ «in Marath non poterant bibere aquas ${ }^{439}$ eo quod essent amarae ${ }^{440}$ » [Ex 15:23] «et murmuravit populus contra ${ }^{441}$ Moysen» [Ex 15:24] «at ille clamavit ad Dominum qui ostendit ei lignum quod cum misisset in aquas ${ }^{442}$ in dulcedinem versae sunt» [Ex 15:25]. Item legitur in libro numeri vigesimo primo ${ }^{443}$ quod cum igniti serpentes percuterent filios Israhel in deserto Moyses iubente Domino serpentem aeneum pro signo ${ }^{444}$ posuit in ligno quem qui percussi inspiciebant sanabantur [cf. Nm 21:6-9]. Item in Ezechiele legitur nono capitulo 445 «cum Dominus mitteret sex viros -id est angelos- in Hierusalem unusquisque habebat vas interius ${ }^{446}$ in manu sua vir quoque unus in medio eorum ${ }^{447}$ habebat atramentarium ad renes eius» [cf. Ez 9:2] cui «dixit Dominus signa thau super frontes virorum ${ }^{448}$ gementium et dolentium super cunctis abominationibus in medio Hier[A 129vb]usalem» [Ez 9:4] et dixit sex viris: transite per ${ }^{449}$ civitatem sequentes eum et percutite «senem adolescentulum et virginem ${ }^{450}$ parvulum et mulieres interficite $[B 10 \mathrm{r}]$ omnem autem hominem ${ }^{451}$ super quem videritis thau ne occidatis» [Ez 9:6]. Thau est extrema ${ }^{452}$ littera antiquarum litterarum hebraici alphabeti et habet similitudinem crucis sic T. Superiori ${ }^{453}$ altitudine caret quia nondum Pilatus adposuerat tabulam in qua scripsit titulum triumphalem nec dum erat in corpore Domini sublimata. Hac cruce quicumque signatus 454 fuerit $^{455}$ fide et opere cum impiis non peribit. Haec omnia, si figurativa non

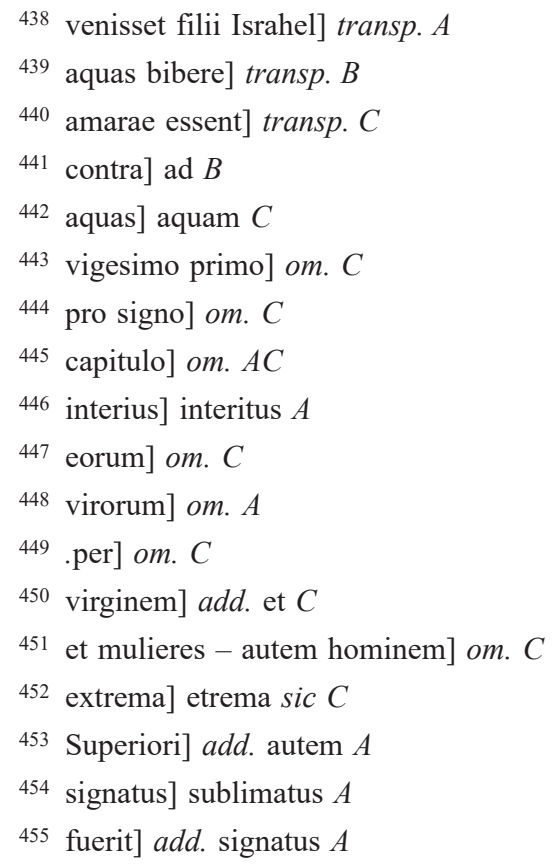


essent, nonne ${ }^{456}$ Deus aliter potuisset aquas amaras indulcorasse nisi per lignum? Nonne aliter potuisset curasse morsus serpentum quam per aspectum serpentis aenei in ligno suspensi? Similiter de tertio si non esset praefiguratio crucis, quare non elegit Dominus ${ }^{457}$ iustos alia littera potius signari quam thau?

\section{De mutatione legis veteris ${ }^{458}$ in novam}

De mutatione legis veteris 459460 in novam dicit Ieremias trigesimo primo capitulo $^{461}$ : «ecce dies veniunt dicit Dominus et feriam domui Israhel et domui Iuda foedus novum non secundum pactum quod pepigi ${ }^{462}$ cum patribus eorum in die qua adprehendi manum eorum ${ }^{463}$ ut educerem eos de terra Aegypti pactum quod irritum fecerunt et ego donatus sum eorum ait Dominus sed hoc erit pactum quod feriam cum domo Israhel post dies illos dicit Dominus ${ }^{464}$ dabo legem meam in visceribus eorum et in corde ${ }^{465}$ eorum scribam eam et ero eis in domum et ipsi erunt mihi in populum et non ${ }^{466}$ docebit ultra ${ }^{467}$ vir proximum [C 43r] suum et vir ${ }^{468}$ fratrem suum di[ $A$ 130ra]cens cognosce Dominum omnes enim cognoscent me a minimo ${ }^{469}$ usque ad maximum ait Dominus quia propiciabor iniquitatibus eorum et peccati ${ }^{470}$ eorum non ero memor amplius» [Ier 31:31-34]. Ubi in latino habetur 'foedus novum' in hebraeo habetur berit hadasa $^{471}$ quod interpretatur nova lex ${ }^{472}$ Mose testante qui in multis locis prae-

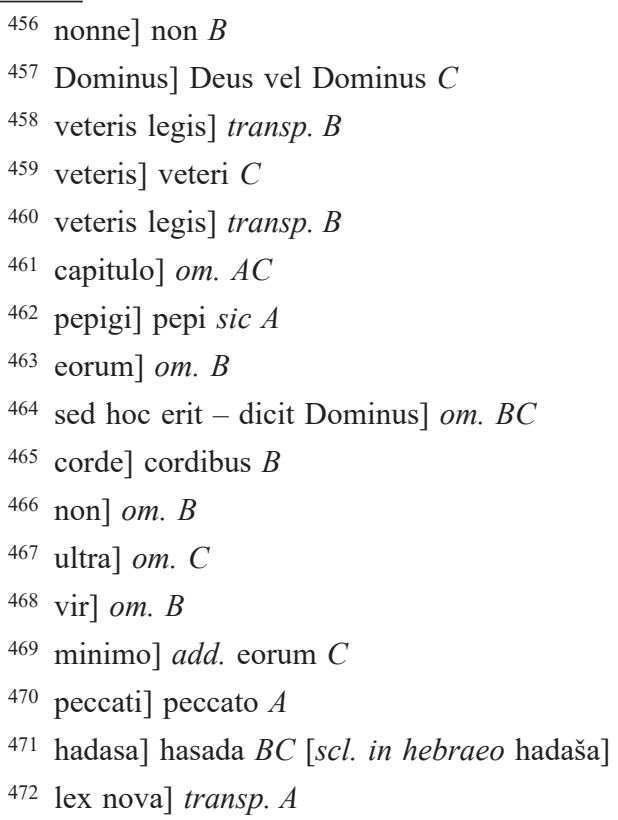


cepta legis suae berith appellatur ${ }^{473}$, unde Paulus eandem auctoritatem Ieremiae sic introducit in epistula ad hebraeos octavo: $« \mathrm{ec}\left[B\right.$ 10v]ce dies venient ${ }^{474}$ dicit Dominus et consummabo super domum Israhel et ${ }^{475}$ super domum Iuda testamentum novum non secundum testamentum quod ${ }^{476}$ feci patribus eorum» $[\mathrm{Hbr}$ 8:8-9] et cetera. Haec omnia referuntur ${ }^{477}$ ad tempus gratiae. Quod autem dicitur: «non docebit ultra vir ${ }^{478}$ proximum suum omnes enim ${ }^{479}$ cognoscent me a minimo usque ad maximum» [Ier 31:34] refertur ad statum gloriae, ubi videbimus Dominum ${ }^{480}$ sicuti $^{481}$ est. Hoc ${ }^{482}$ non ${ }^{483}$ possunt iudaei referre ${ }^{484}$ ad tempora Messiae. Tunc enim docebunt se mutuo, unde legitur in Talmud ${ }^{485}$, in cezer Nassym $^{486}$, id est in secundo ${ }^{487}$ : [Ber 64a] «ibunt de virtute in virtutem» [Ps 83:8 -LXX-]. Ibi dicit rabbi Levi: Non est quies sapientibus in futuro saeculo. Quare? Quia ibunt de loco ad locum ad docendum Talmud et ideo non requiescent. Si iudaeus obicit quod paulo post sequitur in Ieremia: «haec dicit Dominus si mensurari poterunt caeli de sursum et fundamenta terrae deorsum et ego abiciam universum semen Israhel propter omnia quae fecerunt ${ }^{488}$ 》 [Ier 31:37] consentiamus quod Dominus non abiecit universum semen Israhel, sed tamen infideles de quibus ipse dicit per Malachiam primo: «non est mihi voluntas in vobis dicit Dominus exercituum et munus non suscipiam de [A 130rb] manu vestra $a b$ ortu enim solis usque ad occasum magnum est nomen meum in gentibus et in omni loco sanctificatur et offertur nomini meo oblatio munda quia magnum est nomen meum in gentibus» [Mal 1:10-11].

\footnotetext{
473 appellatur] appelat $A B$

474 venient] veniunt $A$

475 et] $a d d$. et $\operatorname{sic} C$

476 quod] om. $C$

477 referuntur] referentur $C$

478 vir ultra] transp. $C$

479 enim] om. $A C$

480 Dominum] eum $B$ om. $C$

481 sicuti] sicut $A$

482 Hoc] Haec $A$

483 non] enim $B$

${ }^{484}$ referre] referri $B$

485 in Talmud] om. BC

486 Nassym] Nazzim $A$

${ }^{487}$ secundo] add. Thalmut $B C$

488 fecerunt] $a d d$. mihi $C$
} 
Ecce manifeste patet reprobatio iudaeorum et commendatio gentium.

Explicit Pharetra contra iudaeos ${ }^{489}$

Recibido: 04/10/2019

Aceptado: 12/03/2020

${ }^{489}$ Explicit - iudaeos] om. $A C$ 